\title{
Strategies for engineering metal-organic frameworks as efficient photocatalysts
}

\author{
Lijuan Shen ${ }^{a, c}$, Ruowen Liang a, Ling $\mathrm{Wu}^{\mathrm{a}, \mathrm{b}, *}$ \\ a State Key Laboratory of Photocatalysis on Energy and Environment, Fuzhou University, Fuzhou 350002, Fujian, China \\ b State Key Laboratory of Structural Chemistry, Fujian Institute of Research on the Structure of Matter, Chinese Academy of Sciences, Fuzhou 350002, \\ Fujian, China \\ ${ }^{c}$ National Engineering Research Center of Chemical Fertilizer Catalyst, Fuzhou University, Fuzhou 350002, Fujian, China
}

\section{A R T I C L E I N F O}

\section{Article history:}

Received 29 August 2015

Accepted 24 September 2015

Published 20 December 2015

\section{Keywords:}

Metal-organic frameworks

Photocatalysis

Ligand

Functionalization

Photosensitization

Co-catalyst

Composite

\begin{abstract}
A B S T R A C T
Environmental pollution and energy deficiency represent major problems for the sustainability of the modern world. Photocatalysis has recently emerged as an effective and environmentally friendly technique to address some of these sustainability issues, although the key to the success of this approach is dependent on the photocatalysts themselves. Based on their attractive physic chemical properties, including their ultrahigh surface areas, homogeneous active sites and tunable functionality, metal-organic frameworks (MOFs) have become interesting platforms for the development of solar energy conversion devices. Furthermore, MOFs have recently been used in a wide variety of applications, including heterogeneous photocatalysis for pollutant degradation, organic transformations, hydrogen production and $\mathrm{CO}_{2}$ reduction. In this review, we have highlighted recent progress towards the application of MOFs in all of these areas. We have collected numerous reported examples of the use of MOFs in these areas, as well as providing some analysis of the key factors influencing the efficiency of these systems. Moreover, we have provided a detailed discussion of new strategies that have been developed for enhancing the photocatalytic activity of MOFs. Finally, we have provided an outlook for this area in terms of the future challenges and potential prospects for MOFs in photocatalysis.
\end{abstract}

(C) 2015, Dalian Institute of Chemical Physics, Chinese Academy of Sciences. Published by Elsevier B.V. All rights reserved.

\section{Introduction}

Environmental pollution and energy shortages have emerged as two major obstacles for the sustainable development of human society. Heterogeneous photocatalysis, which allows for the direct use of abundant solar energy resources to drive reactions, has been proven to be a scientific, effective and green method to alleviate some of the sustainability issues facing our planet [1-5]. Pioneering work on solar energy conver- sion using photocatalysts was conducted by Fujishima et al. in 1972 [1]. Following on from this work, a wide variety of different photocatalysts have been explored, with the vast majority of this work involving the use of inorganic semiconductors such as $\mathrm{TiO}_{2}[6,7]$, $\mathrm{ZnO}[8,9]$, $\mathrm{CdS}[10,12]$ and $\mathrm{Fe}_{2} \mathrm{O}_{3}$ [13]. Despite impressive achievements in this field, photocatalysis with semiconductors is still far from being an economically viable process because of the high recombination of electron-hole pairs and the mismatch between the band gap energy of these sys-

*Corresponding author. Tel/Fax: +86-591-83779105; E-mail: wuling@fzu.edu.cn

This work was supported by the National Natural Science Foundation of China $(21273036,21177024)$ and the National Basic Research Program of China (973 Program, 2014CB239303). 
tems and the sunlight spectrum [14,15]. Moreover, the poor tunability characteristics of traditional semiconductors have further limited their application as photocatalysts [16]. The development of new photocatalytic materials with tunable functionality is therefore highly desired and remains a significant challenge to this field of research.

Metal-organic frameworks (MOFs), which represent a novel type of functional porous material, have aroused considerable interest from researchers working in numerous fields during the past two decades. MOFs, which are also known as 'coordination polymers', are crystalline compounds consisting of infinite lattices. These lattices are composed of metal ions/clusters of inorganic secondary building units (SBU) and organic linkers, which are connected to each other through coordination bonds of moderate strength [17]. MOFs possess several distinct properties such as large surface areas, homogeneous active sites and tunable functionality, which have led to their successful applications in numerous areas, including gas storage $[18,19]$, separation [20], sensing [21,22] and catalysis, as well as several other unrelated applications [23-26]. With regard to the use of MOFs in catalysis, several attempts have been made to explore the potential application of MOFs as a new class of photocatalysts [27-31]. The idea of using MOFs as photocatalysts is mainly based on the followings considerations: (1) some MOFs such as MOF-5 can behave as semiconductors, suggesting that they could be used as charge carrier transporting systems through the photoexcitation of organic linkers or metal clusters [32]; and (2) MOFs can exhibit catalytic activity as a consequence of their unsaturated metal atoms or their catalytically active organic linkers [33,34]. Furthermore, it is possible to functionalize the parent structures of MOFs, allowing for the introduction of extra active sites [35]. Compared with traditional inorganic semiconductors, it is noteworthy that the structures and functionalities of MOFs can be readily tuned via the modification of their organic linkers or metal centers. The ability to tune these systems represents a significant advantage over traditional semiconductors, which opens up the exciting possibility of being able to control the chemical and physical properties of photocatalysts at the molecular level. Moreover, the well-defined crystalline structures of MOFs are beneficial for the characterization and evaluation of the structure-property relationships of these photocatalysts, and therefore provide unprecedented opportunities to examine the basic mechanistic details of photocatalysis chemistry. Based on their unique properties, MOFs show great promise for the development of heterogeneous photocatalysts.

To date, only a few scattered reviews have been published in the literature pertaining to the applications of MOFs in photocatalysis [36-40]. Furthermore, most of these reviews have tended to focus on the roles of MOFs in photocatalysis, with the MOFs being defined as photocatalysts, co-catalysts or hosts for photo redox catalysis. Several other reviews have focused on the specific photocatalytic applications of MOFs, including pollutant degradation, hydrogen generation, $\mathrm{CO}_{2}$ reduction and organic transformations. In this review, we have focused on the material properties of MOFs and the way in which these properties affect the photocatalytic activities of these systems. We have also provided some discussion of the strategies currently available for enhancing the photocatalytic activity of MOFs towards a particular reaction, because we believe that this area is important for the future design of more efficient MOF-based photocatalysts.

\section{MOFs as photocatalysts}

Theoretical calculations have suggested that MOFs are semiconductors or insulators with band gaps in the range of 1.0$5.5 \mathrm{eV}$, which are mainly determined by the differences in the energy levels of the highest occupied molecular orbitals (HOMOs) and lowest unoccupied molecular orbitals (LUMOs) of the linker molecules [41]. Absorption and emission spectroscopic analyses are simple and effective techniques that can be used to determine the relative energies of electronic excited states and these techniques can provide fundamental data pertaining to the semiconducting properties of a specific material. In their pioneering work towards developing a better understanding of the electronic properties of MOFs, Zecchina's group [42] investigated the vibrational, absorption and emission electronic transitions of MOF-5. MOF-5 is composed of $\mathrm{Zn}_{4} \mathrm{O}_{13}$ clusters, with each cluster being surrounded by six terephthalate ligands. An analysis of MOF-5 by optical spectroscopy revealed that its photoluminescence emission could be attributed to an interaction between the terephthalate ligands and the $\mathrm{Zn}_{4} \mathrm{O}_{13}$ clusters. The authors of this report then went on to suggest that the $\mathrm{Zn}_{4} \mathrm{O}_{13}$ clusters were behaving as $\mathrm{ZnO}$ quantum dots (QDs), with the organic portion of the cluster acting as a photon antenna, capable of efficiently transferring energy to the inorganic ZnO-like QD portion of the cluster Fig. 1 shows the model proposed by Zecchina's group, with the different components of MOF-5 behaving as independent quantum dots connected to an aromatic antenna.

In 2007, Garcia's group [32] provided experimental evidence supporting the behavior of MOF-5 as a semiconductor. A laser flash photolysis study of MOF-5 allowed for the detection of a transient spectrum, which was attributed to the charge-separated state arising from the transfer of an electron

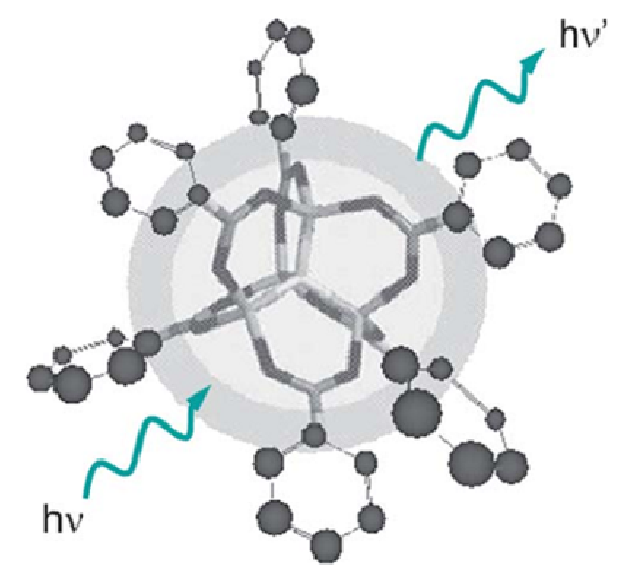

Fig. 1. $\mathrm{Zn}_{4} \mathrm{O}_{13}$ group of MOF-5 $\mathrm{Zn}$ (light grey sticks) and $\mathrm{O}$ (dark grey sticks); the benzene units acting as photon absorbers ( $\mathrm{h} v$ ) can efficiently transfer energy to the inorganic portion of the cluster where the photon emission occurs ( $\left.h v^{\prime}\right)$. 
from the terephthalate unit to the $\mathrm{Zn}_{4} \mathrm{O}$ cluster. The charge-separated state decayed on the microsecond time scale and could be therefore be used to develop new photocatalytic applications for MOF-5. The photogenerated electrons resulting from MOF-5 could be used to reduce electron acceptors, while the holes could be used to oxidize $N, N, N, N$-tetramethyl- $p$-phenylenediamine to the corresponding radical cation. The actual conduction band energy value of MOF- 5 was estimated to be $0.2 \mathrm{~V}$ whilst the NHE gave a band gap of $3.4 \mathrm{eV}$. Upon light absorption, a charge separation process occurred in the ligand-to-metal charge transfer band. The formation of a charge-separated state with electrons in the conduction band (CB) and holes in the valence band (VB) made MOF- 5 behave as a semiconductor. Notably, the charge-separated state of MOF-5 exhibited photocatalytic activity that was comparable in efficiency to that of a P25 titanium dioxide standard towards the degradation of an aqueous solution of phenol. However, this particular study did not investigate the way in which the photogenerated charge carriers might migrate to the surface (defect states) or how they could oxidize or reduce the adsorbates.

To address these limitations, Majima and co-workers [43] investigated the nature of the luminescence transitions observed in MOF-5 nanoparticles (MOF-5_n), as well as evaluating the possibility of interfacial charge transfer from the photoexcited MOF-5_ $n$ to the surface adsorbates. The aim of this study was to develop a better understanding of the photoinduced redox processes of organic compounds on MOFs. The temperature dependencies of the spectral characteristics were elucidated and compared with those of ZnO nanoparticles (NPs). The results indicated that the reorganization energy of the charge-separated state in MOF-5 occurred as a consequence of the larger structural changes required in MOF- 5 compared with $\mathrm{ZnO}$, which was considered as a model of this MOF. Systematic quenching studies of the photoluminescence of MOF-5 using a series of electron donors with different redox potentials (Fig. 2) were conducted with the aim of comparing the different quenching behaviors with that observed for $\mathrm{ZnO}$ as a reference material. This comparison provided useful information about the similarities and differences between the MOF-5 and $\mathrm{ZnO}$ materials. The results generally showed that most of the quenchers exhibited similar relative quenching constants for $\mathrm{ZnO}$ and MOF-5. However, there were three quenchers that exhibited much higher quenching constants for the quenching of the photoluminescence in MOF-5 than they did for $\mathrm{ZnO}$. This contrasting behavior was attributed to the adsorption of these quenchers into the pores of the MOF-5 material, resulting in the pre-concentration of the quencher and the strong binding of these molecules to the MOF-5 sites. This process would then lead to a significant increase in the quenching efficiencies of these materials compared with what would be expected based on their redox potentials. Taken together with the enhanced photocatalytic degradation of phenols by MOFs, the "enhanced quenching" of some electron donors based on the porosity of MOF-5 represents a unique opportunity for shape selectivity effects in photocatalysis. Furthermore this opportunity represents a unique advantage for MOFs compared with traditional nonporous, dense semiconductors.

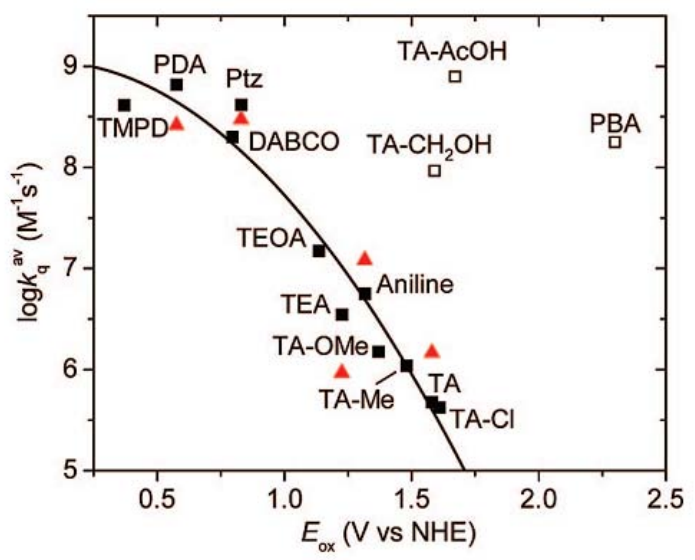

Fig. 2. Relationships between $E_{\text {ox }}$ and $\log k_{\text {avq }}$ for MOF-5_n (black squares) and $\mathrm{ZnO}$ (red triangles). The open squares, which were obtained for MOF-5_n, deviate significantly from those of the other quenchers because of the surface adsorption. Reproduced with permission from Ref. [43]. Copyright 2008, ACS.

Several other MOFs, including MIL and the UiO series of MOFs, have been evaluated as potential photocatalysts [44-51]. Under light irradiation, the organic bridging ligands of these MOFs can serve as antennas to harvest light and activate the metal nodes through a linker-to-metal cluster charge transition (LCCT). These MOFs therefore displayed photocatalytic solar energy conversion activity. Taken together, these excellent examples provide a clear demonstration of the potential for MOFs as photocatalysts for artificial photosynthetic reactions.

\section{Strategies for engineering MOFs photocatalysts}

Photocatalytic processes generally involves three fundamental steps: (1) the absorption of light by the photocatalyst to create electron-hole pairs (photogenerated charge carriers); (2) the separation and migration of electrons and holes to the surface of the photocatalyst; and (3) the initiation of the reduction and oxidation half reactions with the electrons and holes, respectively [52]. In principle, the photocatalytic activity of a catalyst can be enhanced by increasing the absorption of light and decreasing the recombination rate of the photogenerated charge carriers. Several different strategies have recently been developed for enhancing the photocatalytic activity of MOFs under light illumination, including the functionalization and modification of the ligands, sensitization with different sensitizers (e.g., dyes and metal-complex), decoration with a co-catalyst and coupling with a semiconductor, as summarized in Table 1. In the following section, we have provided typical examples of these different strategies for tuning the photocatalytic activity of MOFs, as well as a detailed discussion of the pros and cons of the different strategies.

\subsection{Modification of the organic linkers}

In sharp contrast to traditional semiconductors, MOFs exhibit excellent tunability properties. For example, the optical properties of MOFs can be readily turned by modifying the organic linker (e.g., ligand functionalization), which can allow 
Table 1

Strategy for the engineering of MOFs and their corresponding photocatalytic applications.

\begin{tabular}{|c|c|c|c|c|c|}
\hline \multirow{2}{*}{$\begin{array}{l}\text { Strategy } \\
\text { Ligand modification }\end{array}$} & \multicolumn{2}{|c|}{ MOFs } & \multirow{2}{*}{$\begin{array}{c}\text { Application } \\
\mathrm{CO}_{2} \text { reduction }\end{array}$} & \multirow{2}{*}{$\begin{array}{c}\text { Light source } \\
\text { Visible }\end{array}$} & \multirow{2}{*}{$\begin{array}{l}\text { Ref. } \\
53]\end{array}$} \\
\hline & $-\mathrm{NH}_{2}$ & MIL-125(Ti) & & & \\
\hline & $-\mathrm{NH}_{2}$ & $\mathrm{UiO}-66$ & selective oxidation of alcohols & Visible & {$[54]$} \\
\hline & $-\mathrm{NO}_{2},-\mathrm{Br}$ & $\mathrm{UiO}-66$ & As(III) oxidation & UV-vis & {$[55]$} \\
\hline \multirow[t]{4}{*}{ Photosensitization } & $\mathrm{Pt}(\mathrm{bpydc}) \mathrm{Cl}_{2}$ & MOF-253 & $\mathrm{H}_{2}$ production & Visible & {$[56]$} \\
\hline & $\mathrm{Ru}(\mathrm{tpy})_{2}$ & Ti-MOF & $\mathrm{H}_{2}$ production & Visible & {$[57]$} \\
\hline & Diethylaniline & $\mathrm{NH}_{2} / \mathrm{MIL}-125(\mathrm{Ti})$ & selective oxidation of alcohols & Visible & {$[58]$} \\
\hline & Rhodamine B & $\mathrm{UiO}-66$ & $\mathrm{H}_{2}$ production & Visible & {$[59]$} \\
\hline \multirow[t]{3}{*}{ Metal doping } & Cu ions & ZIF-67 & MO degradation & Visible & {$[60]$} \\
\hline & Ce ions & MIL-101(Cr) & ammonia borane hydrolysis & Visible & {$[61]$} \\
\hline & Ti ions & $\mathrm{NH}_{2}-\mathrm{UiO}-66$ & $\mathrm{CO}_{2}$ reduction & Visible & {$[62]$} \\
\hline \multirow[t]{5}{*}{ Modification with noble metal NPs } & $\mathrm{Pt}$ & Ti-MOF-NH${ }_{2}$ & $\mathrm{H}_{2}$ production & Visible & [63] \\
\hline & $\mathrm{Pd}$ & $\mathrm{NH}_{2}-\mathrm{UiO}-66$ & $\mathrm{Cr}(\mathrm{VI})$ reduction & Visible & {$[64]$} \\
\hline & $\mathrm{Pd}$ & MIL-100(Fe) & PPCPs degradation & Visible & {$[65]$} \\
\hline & $\mathrm{Au}, \mathrm{Pd}, \mathrm{Pt}$ & MIL-100(Fe) & MO degradation & Visible & {$[66]$} \\
\hline & $\mathrm{Au}, \mathrm{Pd}, \mathrm{Pt}$ & MIL-125(Ti) & selective oxidation of alcohol & UV-vis & {$[67]$} \\
\hline \multirow[t]{3}{*}{ Modification with carbon materials } & $\mathrm{GO}$ & MIL-88 (Fe) & MB/ RhB degradation & Visible & {$[68]$} \\
\hline & GO & $\mathrm{UiO}-66\left(\mathrm{NH}_{2}\right)$ & $\mathrm{Cr}(\mathrm{VI})$ reduction & Visible & [69] \\
\hline & GO & MIL-53(Fe) & $\mathrm{Cr}(\mathrm{VI})$ reduction & Visible & {$[70]$} \\
\hline \multirow[t]{5}{*}{ Coupling with semiconductors } & CdS & $\mathrm{UiO}-66\left(\mathrm{NH}_{2}\right)$ & selective oxidation of alcohols & Visible & {$[71]$} \\
\hline & $\mathrm{Fe}_{3} \mathrm{O}_{4}$ & MIL-100(Fe) & MB decolorization & UV-vis & {$[72]$} \\
\hline & $\mathrm{BiVO}_{4}$ & MIL-101(Cr) & RhB degradation & Visible & {$[73]$} \\
\hline & $\mathrm{Ag} / \mathrm{AgCl}$ & ZIF-8 & RhB degradation & Visible & {$[74]$} \\
\hline & $\mathrm{C}_{3} \mathrm{~N}_{4}$ & $\mathrm{UiO}-66$ & $\mathrm{CO}_{2}$ reduction & Visible & {$[75]$} \\
\hline
\end{tabular}

for the facile and effective use of solar light. Amine groups have been studied extensively as ligand substituents because their lone pair of electrons can interact with the $\pi^{*}$-orbitals of the benzene ring, resulting in the donation of electron density to the anti bonding orbitals. This interaction can result in the formation of a new higher energy HOMO level that brings the absorption into the visible region [76]. In 2012, Li et al. [53] first reported the visible-light mediated photocatalytic reduction of $\mathrm{CO}_{2}$ to $\mathrm{HCOO}^{-}$with the amino-functionalized photoactive MOF $\mathrm{NH}_{2}$-MIL-125(Ti). MIL-125(Ti) [ $\left.\mathrm{Ti}_{8} \mathrm{O}_{8}(\mathrm{OH})_{4}(\mathrm{bdc})_{6}\right]$, which contains cyclic octamers of edge and corner sharing $\mathrm{TiO}_{5}(\mathrm{OH})(\mathrm{oc}-$ tahedral), possesses high stability [77]. The introduction of $\mathrm{NH}_{2}$ groups to the organic linkers of this material did not influence the structure of MIL-125(Ti). Infrared analysis showed that the $\mathrm{NH}_{2}$ groups were free from any form of coordination. However, the introduction of the amino functionality did lead to a significant change in the optical absorption properties of $\mathrm{NH}_{2}$-MIL-125(Ti). For example, the absorption edge of MIL-125(Ti) was about $350 \mathrm{~nm}$, while that of the amino functionalized material $\mathrm{NH}_{2}$-MIL-125(Ti) extended to around 550 $\mathrm{nm}$ with an extra absorption band in the visible light region (Fig. 3(a)). The photocatalytic reduction of $\mathrm{CO}_{2}$ was performed in acetonitrile (MeCN) with triethanolamine (TEOA) as a sacrificial agent. $\mathrm{NH}_{2}$-MIL-125(Ti) showed moderate activity towards this reaction under visible light irradiation, with the amount of $\mathrm{HCOO}^{-}$formed by the reaction reaching $8.14 \mathrm{mmol}$ in $10 \mathrm{~h}$. However, MIL-125(Ti) was inactive under similar conditions, because it could not be excited by visible light. The proposed reaction mechanism for the photocatalytic reduction of $\mathrm{CO}_{2}$ over $\mathrm{NH}_{2}$-MIL-125(Ti) is shown in Fig. 3(b). According to the mechanism, irradiation with visible light would lead to a long-lived excited charge-separated state. The subsequent transfer on an electron from the organic ligand to $\mathrm{Ti}^{4+}$ would lead to the formation of $\mathrm{Ti}^{3+}$, which would reduce $\mathrm{CO}_{2}$ to HCOO-.

In 2013, Walsh and co-workers [78] performed a combined experimental and computational study to further elucidate the band structure of MIL-125 and the impact of different functional groups on the $\mathrm{H}_{2} \mathrm{BDC}$ linker. During the course of their study they investigated the impact of increasing the concentration of monoaminated bdc- $\mathrm{NH}_{2}$ on the size of the band gap of MIL-125 by varying the ratio of bdc and bdc- $\mathrm{NH}_{2}$ linkers (i.e., 10\%, 50\% and $100 \%$ bdc- $\mathrm{NH}_{2}$, which equated to around 1,6 and 12 bdc- $\mathrm{NH}_{2}$ linkers per unit cell). All of the samples had similar band gaps of around $2.6 \mathrm{eV}$, but their molar extinction coefficients increased significantly in proportion to their bdc- $\mathrm{NH}_{2}$ content, which suggested that a single amino group was responsible for the reduced band gap of the monoaminated series of MIL-125 analogues. Electronic structure calculations on the same series of monoaminated MIL-125- $\mathrm{NH}_{2}$ solids were performed using density functional theory (DFT). The results showed that the VB of MIL-125- $\mathrm{NH}_{2}$ changed following the amination of the linker, whilst the lower $C B$ value was unchanged (Fig. 4(d)). Furthermore, the modified VB was $1.2 \mathrm{eV}$ greater than that of MIL-125, indicating that the degree of amination did not affect the band gap. The impact of the addition of a second amino group to the linker was also calculated by selecting diaminated bdc- $\left(\mathrm{NH}_{2}\right)_{2}$ as a linker and constructing a $10 \%$-MIL-125-( $\left.\mathrm{NH}_{2}\right)_{2}$ model based on a mixture of $10 \%$ bdc- $\left(\mathrm{NH}_{2}\right)_{2}$ and $90 \%$ bdc. A larger red shift was found with a 
(a)

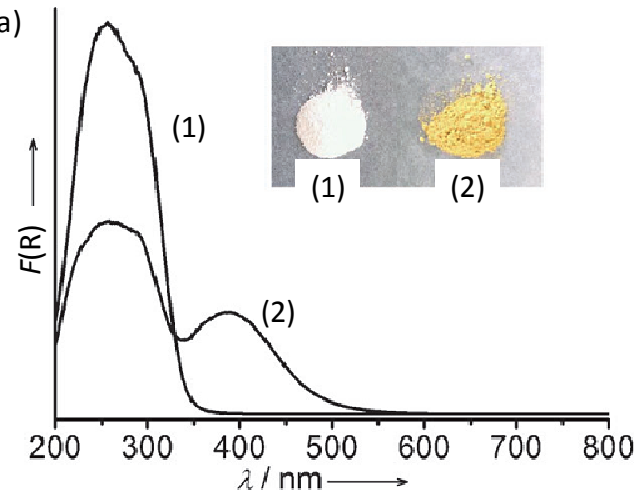

(b)

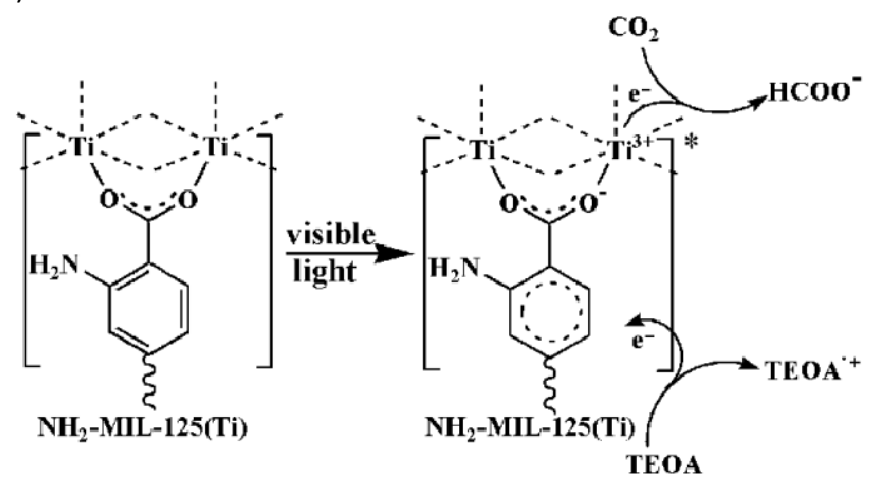

Fig. 3. (a) UV-vis spectra of (1) MIL-125(Ti) and (2) $\mathrm{NH}_{2}$-MIL-125(Ti). (b) Proposed mechanism for the photocatalytic reduction of $\mathrm{CO}_{2}$ over $\mathrm{NH}_{2}$-MIL-125(Ti) under visible light irradiation. Reproduced with permission from Ref. [53]. Copyright 2012, Wiley.

(a)

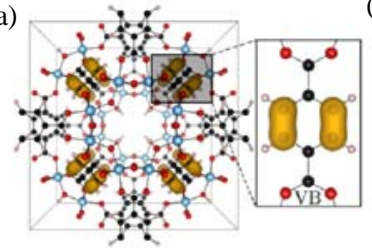

(b)

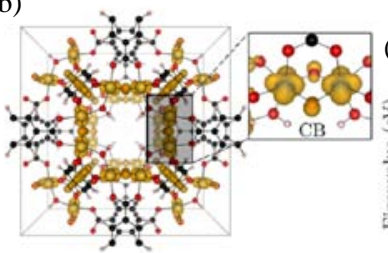

(c)

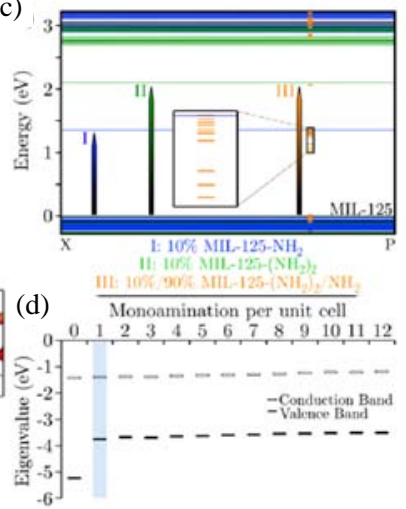

(e)

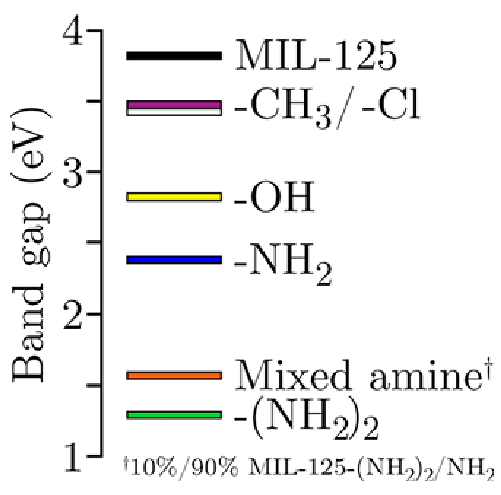

Fig. 4. (a, b) Frontier electron density of unsubstituted MIL-125. (c) PBE sol band structures for synthetic MIL-125 (black), 10\%-MIL-125-(NH $)_{2} /$ $90 \%-M I L-125-\mathrm{NH}_{2}$ (orange), 10\%-MIL-125- $\mathrm{NH}_{2}$ (blue) and the theoretical 10\%-MIL-125- $\left(\mathrm{NH}_{2}\right)_{2}$ (green). The orange bands, which have been truncated to improve the clarity of the band structures, maintained flat characteristics. (d) HSE06-calculated VB and CB energies of the MIL-125-NH 2 models containing increasing numbers of bdc- $\mathrm{NH}_{2}$ linkers. (e) HSE06-predicted band gaps of MIL-125 (black) and its analogues containing the functionalized bdc linkers. Reproduced with permission from Ref. [78]. Copyright 2013, ACS.

resultant band gap of $1.28 \mathrm{eV}$ for the diaminated MIL-125(Ti), which was attributed to the increase in the aromatic electronic density resulting from the presence of two electron donating amino groups on the ring. The authors conducted further in silico experiments on MIL-125 using the diaminated linker bdc- $\left(\mathrm{NH}_{2}\right)_{2}$ and several other functional groups (i.e., $-\mathrm{OH},-\mathrm{CH}_{3}$, $-\mathrm{Cl}$ ) as alternative substituents for controlling the optical response of MIL-125(Ti). The introduction of $10 \%$ bdc- $\mathrm{R}(\mathrm{R}=$ $-\mathrm{OH},-\mathrm{CH}_{3},-\mathrm{Cl}$ ) resulted in flexible control over the band gap between 3.5 and $2.4 \mathrm{eV}$ (Fig. 4(e)). This study therefore provided a clear understanding of the specific role of the $-\mathrm{NH}_{2}$ group of the monoaminated bdc- $\mathrm{NH}_{2}$ linker in terms of its ability to lower the band gap of MIL-125, and highlighted the possibility of tuning the optical response of MOFs through the rational functionalization of the linking unit.

MOFs capable of absorbing visible light have also been prepared using a Zr-based MOF (UiO-66) by substituting the organic linker $\mathrm{H}_{2} \mathrm{BDC}$ with 2-amino-benzenedicarboxylic acid (H2ATA). In 2013, Wu and co-workers [54] employed two highly water stable $\mathrm{Zr}$-based MOFs (UiO-66 and its derivative UiO-66( $\left(\mathrm{NH}_{2}\right)$ ) as multifunctional photocatalysts. UiO-66 and
$\mathrm{NH}_{2}$-UiO-66 are highly crystalline isoreticular MOFs, which are composed of $\mathrm{Zr}_{6}(\mathrm{O})_{4}(\mathrm{OH})_{4}\left(\mathrm{CO}_{2}\right)_{12}$ secondary building units [79]. The results of this study revealed that UiO-66 could only be photoexcited under ultraviolet light irradiation, making it unfavorable in terms of its ability to fully utilize solar energy. The amino functionalization of UiO-66 led to the formation of a new absorption band in the optical spectrum of $\mathrm{UiO}-66\left(\mathrm{NH}_{2}\right)$, which was attributed to the chromophore of the BDC-NH 2 ligand. The photoabsorption edge of UiO-66( $\left.\mathrm{NH}_{2}\right)$ had therefore shifted to the visible light region after the introducing of the amino group $\left(-\mathrm{NH}_{2}\right)$, which was consistent with its color changing from white to yellow (inset in Fig. 5). This red-shift in the light absorption characteristics resulted in enhanced photocatalytic activity. For example, UiO-66 $\left(\mathrm{NH}_{2}\right)$ performed as an efficient multifunctional visible-light-driven catalyst with high stability and considerable recyclability in both the photocatalytic selective oxidation of alcohols to aldehydes using molecular oxygen as oxidant and catalytic reduction of aqueous $\mathrm{Cr}(\mathrm{VI})$ to $\mathrm{Cr}$ (III) under ambient conditions. Control experiments showed that UiO-66 was catalytically inactive in these reactions under identical conditions, which indicated that the visi- 


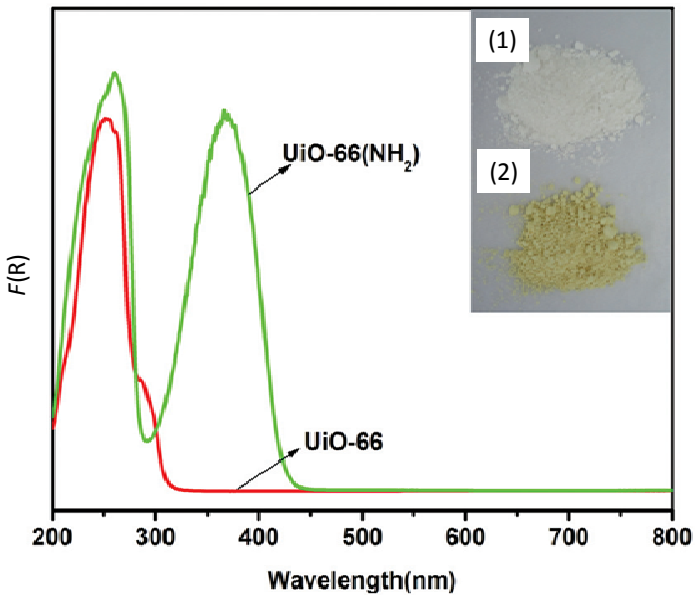

Fig. 5. UV-vis spectra of UiO-66 and UiO-66 $\left(\mathrm{NH}_{2}\right)$; photographs in the inset are images of UiO-66 (1) and UiO-66( $\left.\mathrm{NH}_{2}\right)(2)$. Reproduced with permission from Ref. [54]. Copyright 2013, RSC.

ble-light-driven photocatalytic activity of the UiO-66( $\left.\mathrm{NH}_{2}\right)$ catalyst was induced by the introduction of the amino functionality.

In 2014, Wu's group [55] carried out a follow-up study involving the fabrication of an isoreticular series of functionalized UiO-66- $\mathrm{X}\left(\mathrm{X}=\mathrm{H}, \mathrm{NH}_{2}, \mathrm{NO}_{2}, \mathrm{Br}\right)$ compounds. UiO-66-X $\left(\mathrm{X}=\mathrm{NH}_{2}\right.$, $\mathrm{NO}_{2}, \mathrm{Br}$ ) were synthesized in a manner analogous to that of UiO-66 by replacing terephthalic acid $\left(\mathrm{H}_{2} \mathrm{BDC}\right)$ with equivalent molar amounts of $\mathrm{H}_{2} \mathrm{~N}-\mathrm{H}_{2} \mathrm{BDC}, \mathrm{O}_{2} \mathrm{~N}-\mathrm{H}_{2} \mathrm{BDC}$ and $\mathrm{Br}-\mathrm{H}_{2} \mathrm{BDC}$, respectively. The successfully incorporation of these functional groups on the linkers was confirmed by IR spectroscopy. A subsequent investigation of the physicochemical properties of UiO-66 and its functionalized derivatives demonstrated that these MOFs had high levels of thermal and chemical stability, even when the functional groups were incorporated at the linker units. The optical absorption properties of the UiO-66-X compounds were investigated by UV-vis spectroscopy (Fig. 6(a)). The main absorption band of UiO-66 was located in the UV region (ca. $320 \mathrm{~nm}$ ) and was attributed to a ligand-to-metal charge transfer (LMCT) process. The introduction of functional groups to the aromatic ring had a pronounced effect on the optical properties of these materials. For example, the absorption edges for UiO-66-X (X $=\mathrm{NH}_{2}, \mathrm{NO}_{2}$ and $\left.\mathrm{Br}\right)$ were around 450, 400 and $360 \mathrm{~nm}$, respectively. The results of a series of batch experiments showed that As(III) could be efficiently oxidized to $\mathrm{As}(\mathrm{V})$ over UiO-66 under simulated sunlight irradiation conditions. Notably, the introduction of substituents to the core scaffold of UiO-66 had a significant impact on its photocatalytic activity. The reaction rates resulting from the different substituents formed a linear correlation with the Hammett coefficients of the substituents themselves (Fig. 6(b)). An analogous trend was also observed for the photocatalytic reduction of $\mathrm{Cr}(\mathrm{VI})$ to $\mathrm{Cr}(\mathrm{III})$ over UiO-66- $\mathrm{X}\left(\mathrm{X}=\mathrm{H}, \mathrm{NH}_{2}, \mathrm{NO}_{2}\right.$ and $\left.\mathrm{Br}\right)$. These results therefore show that UiO-66-based catalysts bearing electron-donating substituent were more reactive than those baring electron-withdrawing substituents, which appeared to attenuate the photoreactivity of Ui0-66. The results of this study had a significant impact in the field, because they
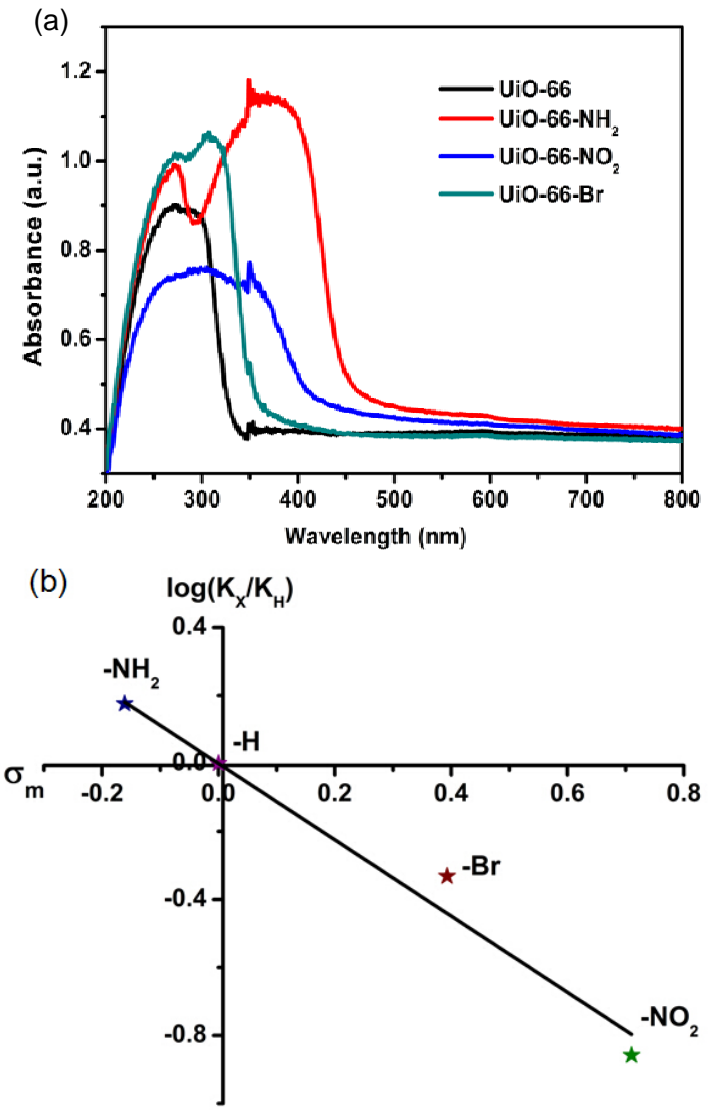

Fig. 6. (a) UV-vis absorption spectra of UiO-66-X $\left(X=H, \mathrm{NH}_{2}, \mathrm{NO}_{2}\right.$ and $\mathrm{Br}$ ); (b) Hammett plot for oxidation of aqueous As(III) with UiO-66-X (X $=\mathrm{H}, \mathrm{NH}_{2}, \mathrm{NO}_{2}$ and $\mathrm{Br}$ ) catalysts. Reproduced with permission from Ref. [55]. Copyright 2015, RSC.

not only showed that different ligand substituents could be used to modify the light-harvesting properties of MOFs, but also showed that the electronic effects of the substituents could have a significant impact on their photocatalytic activity.

\subsection{Photosensitization}

The use of photosensitizers such as organo metallic complexes represents another effective strategy for enhancing the absorption of visible light $[80,81]$. In 2013, Xu and co-workers [56] reported the fabrication of MOF-253-Pt-via the immobilization of a platinum complex on a 2,2'-bipyridine-based microporous MOF (MOF-253) using a post-synthetic modification (PSM) strategy. The absorption edge of MOF-253-Pt (410 nm) showed an obvious red shift compared with that of MOF-253 $(380 \mathrm{~nm})$, which was attributed to the binding of $\mathrm{PtCl}_{2}$ to bipyridine (Fig. 7(a)). The photocatalytic activity of MOF-253-Pt for $\mathrm{H}_{2}$ evolution was evaluated under visible-light irradiation with TEOA as a sacrificial electron donor. The results of a series of control experiment showed that MOF-253-Pt, TEOA and visible light were all critical to the success of the reaction, highlighting the photocatalytic nature of the reaction. As shown in Fig. 7(b,) Pt-MOF-253 exhibited much higher photocatalytic activity than the parental compound MOF-253. Moreover, the solvent had a significant influence on the photocatalytic activity 

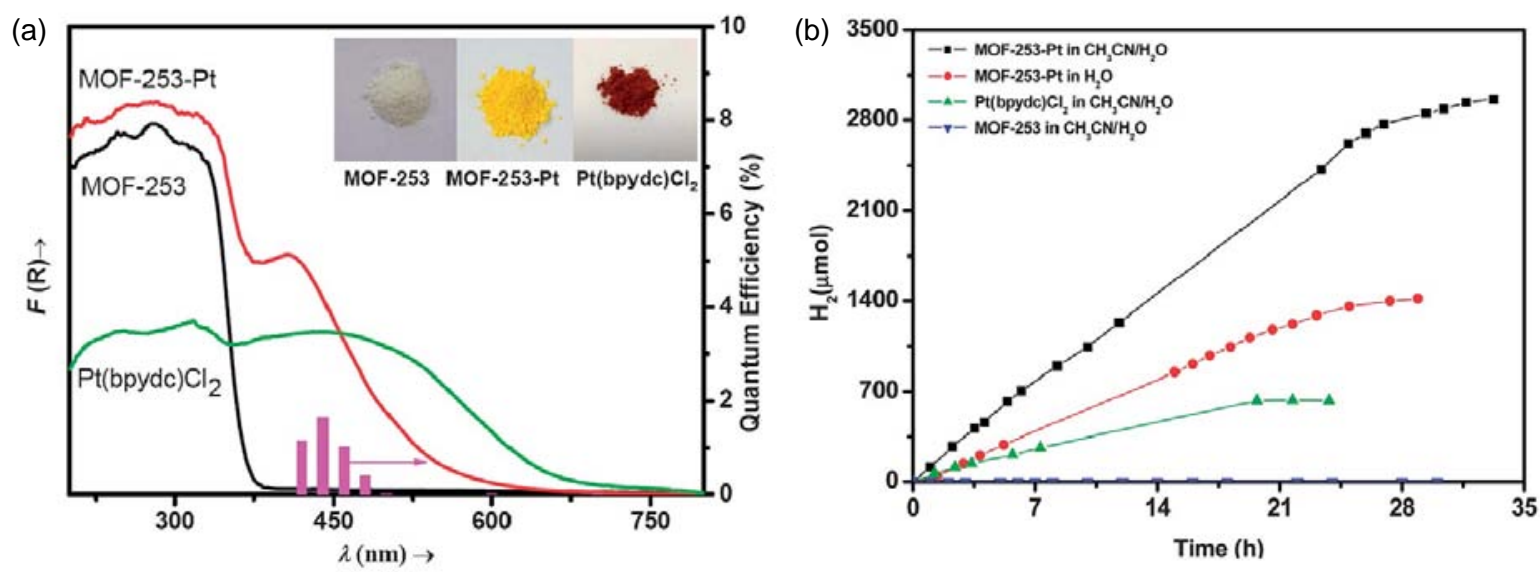

Fig. 7. (a) UV-vis spectra of MOF-253, Pt-MOF-253, and $\mathrm{Pt}(\mathrm{bpydc}) \mathrm{Cl}_{2}$ as well as the quantum efficiencies of hydrogen evolution for MOF-253-Pt at different wavelengths. The inset shows the colors of the samples. (b) Photocatalytic $\mathrm{H}_{2}$ evolution over MOF-253-Pt in $\mathrm{H}_{2} \mathrm{O}$, as well as MOF-253-Pt, $\mathrm{Pt}\left(\right.$ bpydc) $\mathrm{Cl}_{2}$ and MOF-253 in $\mathrm{CH}_{3} \mathrm{CN} / \mathrm{H}_{2} \mathrm{O}$, respectively. Reproduced with permission from Ref. [56]. Copyright 2013, RSC.

of the samples. For example, the use of a co-solvent $\left(\mathrm{CH}_{3} \mathrm{CN} / \mathrm{H}_{2} \mathrm{O}\right.$ at $\left.1: 1, v / v\right)$ led to a significant improvement in $\mathrm{H}_{2}$ evolution. The monomer complex $\mathrm{Pt}(\mathrm{bpydc}) \mathrm{Cl}_{2}$ was also evaluated under the same conditions for comparison. The amount of $\mathrm{H}_{2}$ produced using MOF-253-Pt was 4.7 times greater than that obtained over $\mathrm{Pt}(\mathrm{bpydc}) \mathrm{Cl}_{2}$. The higher photocatalytic activity of MOF-253-Pt was attributed to three key factors, including (1) the formation of interactions between the partially separated Pt...Pt pairs; (2) enhanced electron transfer efficiency within the porous framework; and (3) the reduced decomposition rate of the anchored $\mathrm{Pt}(\mathrm{bpy}) \mathrm{Cl}_{2}$ complex within the MOF. However, one of the main limitations to the use of MOF-253-Pt as a photocatalyst for the visible-light-mediated evolution of hydrogen was found to be its obvious deactivation after repeated operations.

Matsuoka and co-workers [57] recently used a bis(4-(4-carboxyphenyl)-terpyridine)-Ru(II) complex $\left(\mathrm{Ru}\left(\mathrm{tpy}_{2}\right)\right.$ as a bridging ligand to synthesize a $\mathrm{Ru}$ complex-incorporated Ti-based MOF (Ti-MOF-Ru(tpy)2). Diffuse-reflectance and cyclic voltammetry measurements showed that $\mathrm{Ru}(\mathrm{tpy})_{2}$ possessed a wider absorption band in the visible-light region and a lower HOMO level than those of $\mathrm{BDC}-\mathrm{NH}_{2}$. Notably, the local structure of the Ru complex remained unchanged following the formation of Ti-MOF-Ru(tpy)2. Furthermore, the Ti-MOF-Ru(tpy) 2 material exhibited photocatalytic activity for the production of $\mathrm{H}_{2}$ from water containing TEOA, which was added as a sacrificial electron donor, under visible-light irradiation conditions. Enhanced photocatalytic activity was also observed when Pt NPs were deposited onto the surface of Ti-MOF-Ru(tpy) 2 as a co-catalyst. In contrast, Ru(tpy) 2 showed no photocatalytic activity under the same conditions. For comparison, the authors also prepared $\mathrm{Ru}(\mathrm{tpy})_{2}-\mathrm{TiO}_{2}$ by the adsorption of $\mathrm{Ru}(\text { tpy) })_{2}$ onto Degussa $\mathrm{P} 25 \mathrm{TiO}_{2}$. However, no $\mathrm{H}_{2}$ production was observed over this material. The failure of $\mathrm{Ru}(\mathrm{tpy})_{2}-\mathrm{TiO}_{2}$ as a photocatalyst for this reaction could be attributed to $\mathrm{Ru}(\mathrm{tpy})_{2}$ preventing desorption from the $\mathrm{TiO}_{2}$ surfaces under the reaction conditions, which would obstruct the transfer of photogenerated electrons from $\mathrm{Ru}(\text { tpy })_{2}$ to $\mathrm{TiO}_{2}$. This result therefore highlights an important advantage of MOF-based photocatalytic systems, where the titanium-oxo clusters and Ru(tpy) 2 were strongly connected. Impressively, Ti-MOF-Ru(tpy) 2 showed high levels of activity and structural stability. Furthermore, no obvious decrease was observed in the photocatalytic activity after three cycles. X-ray diffraction (XRD) analysis confirmed that the structure of Ti-MOF-Ru(tpy)2 remained unchanged after the reaction. This report was the first example of a photocatalytic $\mathrm{H}_{2}$ production system involving the use of MOF materials under visible light irradiation condition at wavelengths up to $620 \mathrm{~nm}$.

The main limitation of using transition-metal complexes as photosensitizers is their high cost. Based on this limitation, several groups have investigated the use of cheap dyes or dye-like moieties as promising alternatives for the photosensitization of MOFs. Dye-sensitization has been widely applied to semiconductor photocatalysts to improve their light harvesting properties. The main drawback to this technique is that the external surface area available for reaction is limited in size [82-84]. In the case of MOFs, efficient sensitizing can be combined with an extremely high concentration of active sites in their pore space [85]. In 2013, Gascon et al. [58] developed a straight forward PSM to improve the optical absorption of $\mathrm{NH}_{2}$-MIL-125(Ti). Briefly, an organic linker was functionalized with adiazonium salt and subsequently reacted with a nucleophilic species such as diethylaniline to allow for the incorporation of dye-like moieties into the MOF scaffold. In this way, Gascon's group successfully synthesized methyl red-MIL-125(Ti) as a new material, which displayed much higher light absorption than the parent compound $\mathrm{NH}_{2}$-MIL-125(Ti). For example, the UV-vis spectrum of $\mathrm{NH}_{2}$-MIL-125(Ti) contained two absorption bands at 325 and $465 \mathrm{~nm}$, whilst the UV-vis spectrum of red-MIL-125(Ti) showed a significant red-shift in the absorption edge up to almost $700 \mathrm{~nm}$. The photocatalytic activity of MR-MIL-125(Ti) was assessed for the selective oxidation of benzyl alcohol to benzaldehyde under visible light illumination. The MR-MIL-125(Ti) framework displayed enhanced photocatalytic 
activity compared with the parent framework. This improvement in the photocatalytic activity was attributed to the enhanced optical absorption of the solid resulting from the extended conjugation of the aromatic system of the ligand (Fig. 8).

A more convenient method of achieving dye sensitization is to add a dye directly to the reaction system. Yan's group [59] recently reported that the stable UiO-66(Zr) MOF could be sensitized to the visible-light-mediated photocatalytic production of $\mathrm{H}_{2}$ through the adsorption or direct addition of rhodamine $\mathrm{B}$ $(\mathrm{RhB})$ dye. Notably, UiO-66(Zr) did not show any absorption in the visible-light region. After being sensitized by RhB, the absorption intensity of UiO-66(Zr) was greatly improved and the absorption range was expanded to about $600 \mathrm{~nm}$. With TEOA as a sacrificial electron donor, $\mathrm{RhB} / \mathrm{UiO}-66(\mathrm{Zr})$ exhibited photocatalytic activity towards $\mathrm{H}_{2}$ production under visible-light, indicating that the addition of RhB dye to the solution had successfully sensitized UiO-66(Zr), despite the formation of weak interactions between the RhB dye and the MOF. Further study showed that the amount of dye added to the reaction had a significant influence on the photocatalytic activity. Using Pt as a co-catalyst, the adsorption or direct addition of dye led to a 30or 26-fold increase in the photocatalytic activity, respectively, compared with bare Pt@UiO-66(Zr). A plausible mechanism has been proposed for this reaction, which is shown in Fig. 9. Briefly, the RhB dye molecules adsorbed onto the surface of Pt@UiO-66(Zr) would become excited under visible-light irradiation, and the excited electrons would be transferred to the LUMO of UiO-66(Zr). The deposition of Pt NPs on the surface of UiO-66(Zr) would lead to the formation of a Schottky barrier at the interface between the UiO-66(Zr) particles and the Pt NPs. The trapped electrons in the UiO-66(Zr) would then be transferred to the Pt NPs, which would be spatially separated into $\mathrm{RhB}^{+}$and electrons. This would therefore promote the transfer and separation of the photogenerated carriers, leading to an improvement in the photocatalytic activity of the sample for $\mathrm{H}_{2}$ evolution. The excited $\mathrm{RhB}^{*}$ could also inject electrons directly into $\mathrm{Pt}$ to produce $\mathrm{H}_{2}$. Furthermore, the resulting $\mathrm{RhB}^{+}$species could obtain electrons from the electron donor TEOA and recovered to their ground state.

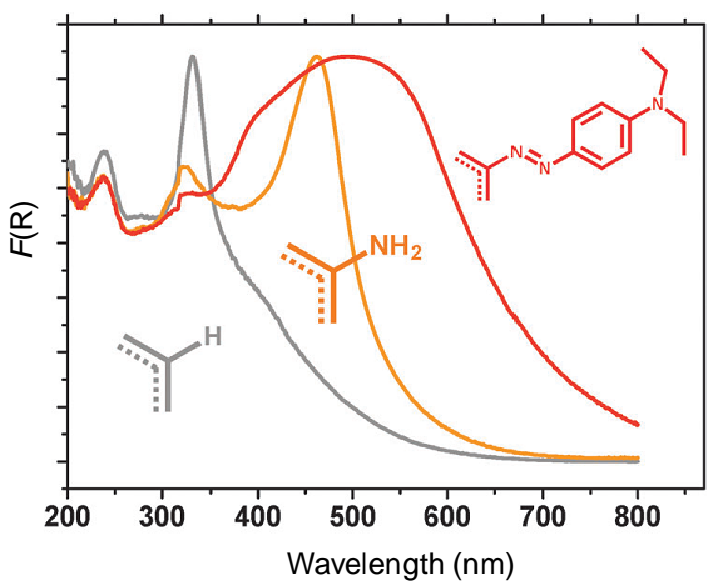

Fig. 8. Diffuse reflectance spectra of the MIL-125(Ti) (grey), $\mathrm{NH}_{2}$-MIL-125(Ti) (orange) and MR-MIL-125(Ti) (red). Reproduced with permission from Ref. [58]. Copyright 2013, RSC.

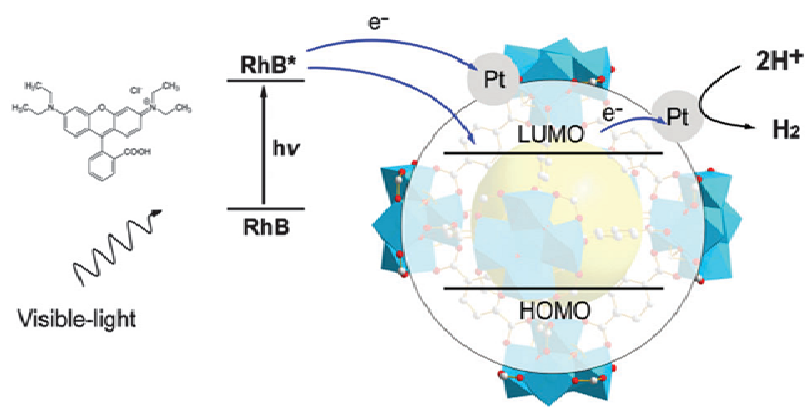

Fig. 9. Proposed mechanism for the photocatalytic production of $\mathrm{H}_{2}$ over RhB-sensitized Pt@UiO-66(Zr) under visible-light illumination. Reproduced with permission from Ref. [59]. Copyright 2014, RSC.

\subsection{Metal doping}

Metal doping has been proven to be an effective method for enhancing the catalytic performances of semiconductor-based photocatalysts [86-88]. This strategy can also be extended to MOF-based photocatalysts. In 2012, Zhang and co-workers [60] developed a doping strategy to tune the photocatalytic activity of ZIFs by modifying their structural compositions in a way that allowed them to keep their porosity whilst being able to act directly as visible light responsive photocatalysts. A Co-2-methylimidazole framework ZIF-67 with the SOD topology was selected as a model system for investigation, and additional $\mathrm{Cu}$ ions were doped into its framework. The results of UV-vis diffuse reflection measurements showed that the band gaps of ZIF-67 and Cu/ZIF-67 were 1.98 and $1.95 \mathrm{eV}$, respectively. These materials were subsequently employed for methyl orange (MO) photodegradation under visible-light irradiation. $\mathrm{Cu} /$ ZIF-67 showed excellent photocatalytic activity for the degradation of MO, with the MO in the solution being almost completely degraded after $25 \mathrm{~min}$ (Fig. 10). Moreover, $\mathrm{Cu} /$ ZIF-67 remained stable during the cycle experiment with a nearly constant photocatalytic degradation rate. In contrast, ZIF-67 showed much lower photocatalytic activity under the same reaction conditions. Although the structural details of this Cu-doped ZIF-67 phase remain unclear, the enhanced photocatalytic activity exhibited by $\mathrm{Cu} / \mathrm{ZIF}-67$ was unambiguous. This result therefore highlights the importance of $\mathrm{Cu}$-doping for tuning the photocatalytic activity of ZIF-67, despite the fact that ZIF-67 and Cu/ZIF-67possessed the same topological structures and similar band gaps.

Similarly, Yamashita et al. [61] synthesized a new photoactive cerium-doped chromium-based amine-functionalized MOF (CeMIL-101) from $\mathrm{Ce}\left(\mathrm{NO}_{3}\right)_{3}$ and $\mathrm{Cr}\left(\mathrm{NO}_{3}\right)_{3}$ via a direct hydrothermal treatment process. The doping of Ce ions into MIL-101 did not lead to significant changes in the structural, textural or optical properties of the original material. The photocatalytic activity of CeMIL-101 was evaluated for the hydrolysis of ammonia borane under visible-light irradiation. The additions of Pd nanoparticles (NPs) to these MOFs resulted in the formation of Pd/MlL-101 and Pd/CeMlL-101, which showed much higher activity than the parent materials. A comparison of the photocatalytic activities of Pd/MlL-101 and Pd/CeMlL-101 revealed 
(a)

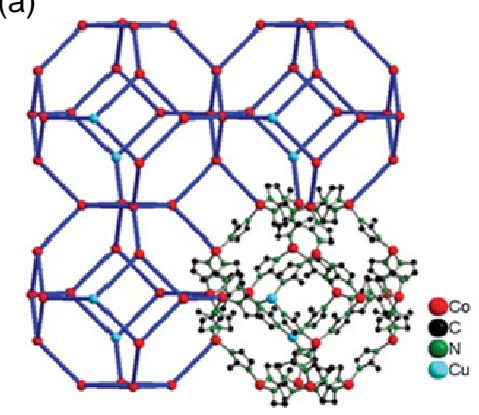

(b)

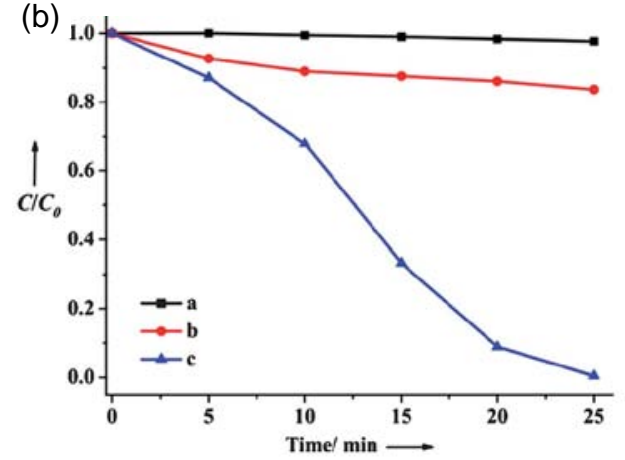

Fig. 10. (a) SOD-type framework structure of Cu/ZIF-67. (b) Photodegradation of MO on ZIF-67 and Cu/ZIF-67 under visible-light illumination in the presence of $\mathrm{H}_{2} \mathrm{O}_{2}$. Reproduced with permission from Ref. [60]. Copyright 2012, RSC.

that the latter exhibited much greater catalytic activity than the former under the same reaction conditions. The authors of this report suggested that the synergetic effects of the different photo-generated charge-separated species would promote the recycling of the $\mathrm{Ce}^{4+} / \mathrm{Ce}^{3+}$ redox pathway. This pathway would then lead to the production of hydroxyl radicals, superoxide anions and electron rich Pd NPs, which the authors cited as the main reasons for the enhanced activity of Pd/CeMlL-101.

Doped metal cations can also act as electron mediators to facilitate charge transfer processes, which can lead to an improvement in the photocatalytic activity of MOFs. Li's group [62] recently prepared Ti-substituted $\mathrm{NH}_{2}$-Uio-66(Zr) (denoted as $\mathrm{NH}_{2}$-UiO-66(Zr/Ti)) by a post-synthetic exchange method. Subsequent X-ray absorption fine structure analyses confirmed the successful substitution of $\mathrm{Zr}$ by Ti. The substitution of the $\mathrm{Zr}$ with $\mathrm{Ti}$ ions led to an increase in the photocatalytic activity of $\mathrm{NH}_{2}$-UiO-66(Zr) towards $\mathrm{CO}_{2}$ reduction. The amount of HCOO-produced over $\mathrm{NH}_{2}$-UiO-66(Zr/Ti)-120-16 following 10 $\mathrm{h}$ of irradiation was $5.8 \mathrm{mmol} \mathrm{mol}^{-1}$, which was 1.7 -fold greater than that observed over $\mathrm{NH}_{2}$-UiO-66(Zr) under similar conditions. $\mathrm{NH}_{2}$-UiO-66(Zr/Ti)-120-16 also showed enhanced activity towards a photocatalytic $\mathrm{H}_{2}$ evolution reaction, with a 1.5-fold increase in the amount of $\mathrm{H}_{2}$ evolved after $9 \mathrm{~h}$ compared with $\mathrm{Pt} / \mathrm{NH}_{2}-\mathrm{UiO}-66(\mathrm{Zr})$. A DFT calculation was used to elucidate the cause of the enhanced activity over $\mathrm{NH}_{2}$-UiO-66(Zr/Ti), and the results indicated that the substituted Ti moiety could act as an electron mediator to promote an electron transfer from ATA to the Zr center. Based on experimental observations and the results of theoretical calcula- tions, the enhanced photocatalytic activity of the Ti-substituted $\mathrm{NH}_{2}$-UiO-66(Zr/Ti) material can be described as follows (Fig. 11). Upon visible-light irradiation, the ATA ligand would be excited. The excited ATA would transfer electrons to the $\mathrm{Zr}-\mathrm{O}$ oxo-metal cluster in $\mathrm{NH}_{2}$-UiO-66(Zr). The substitution of some of the $\mathrm{Zr}^{4+}$ centers with $\mathrm{Ti}^{4+}$ would mean that the electrons could be transferred to either $\mathrm{Zr}^{4+}$ or $\mathrm{Ti}^{4+}$. The results of a series of calculations showed that the probability of electrons being transferred to $\mathrm{Ti}^{4+}$ was higher than that of $\mathrm{Zr}^{4+}$, indicating that the formation of excited $\left(\mathrm{Ti}^{3+} / \mathrm{Zr}^{4+}\right)_{6} \mathrm{O}_{4}(\mathrm{OH})_{4}$ was the most probable outcome of the electron transfer process. The $\mathrm{Ti}^{3+}$ ions would then act as electron donors and donate electrons to $\mathrm{Zr}^{4+}$ to form $\mathrm{Ti}^{4+-}-\mathrm{Zr}^{3+}$. In this way, the substituted $\mathrm{Ti}$ center would help to improve the interfacial charge transfer from excited ATA to the Zr-O oxo-clusters, which would be beneficial for improving the visible-light photoactivity of the $\mathrm{NH}_{2}-\mathrm{UiO}-66(\mathrm{Zr} / \mathrm{Ti})$ photocatalyst.

\subsection{MOFs photocatalysts decorated with co-catalysts}

MOFs have been proven to be effective photoactive catalysts, and their optical properties can be readily tuned towards visible-light-mediated processes. However, several challenges still exist with regards to the efficient application of MOFs, such as the high recombination probability of photoexcited charge carriers $[89,90]$. One strategy for improving the photocatalytic performances of MOFs involves decorating their surfaces with co-catalysts, especially noble metal NPs and graphene, which could accept photoinduced electrons from MOFs, and consequently promote the necessary charge separation processes.

\subsubsection{MOFs decorated with noble metal NPs}

It is generally accepted that methods capable of improving the utilization efficiency of photogenerated electron-hole pairs and prolonging the lifetime of photogenerated charge-carriers could enhance the photocatalytic activity MOFs. In this regard, noble-metal NPs could be good candidate materials as photocatalytic promoters. Noble-metal NPs can be used to efficiently separate the photoexcited electron-hole pairs of photocatalysts because of their high Fermi energy levels [91-94]. Moreover, MOF-based photocatalysts are good supports for the immobilization of metal NPs because of their ultrahigh surface areas and well-defined pore structures, which are beneficial for controlling the limited growth of metal NPs, leading to highly reactive

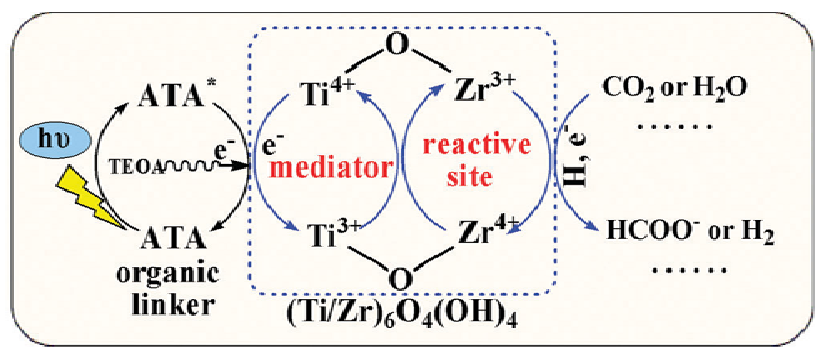

Fig. 11. Proposed mechanism for the enhanced photocatalytic activity of $\mathrm{NH}_{2}$-Uio-66(Zr/Ti). Reproduced with permission from Ref. [62]. Copyright 2015, RSC. 
monodispersed metal NPs. In 2012, Matsuoka and co-workers [63] reported the Pt@photoactive MOF (Ti-MOF-NH 2 ) assemblies for $\mathrm{H}_{2}$ evolution under visible-light irradiation $(\lambda \geq 420$ $\mathrm{nm}$ ) with TEOA as a sacrificial reductant. After $9 \mathrm{~h}$ of irradiation in the presence of the Pt/Ti-MOF-NH 2 photocatalyst at room temperature, the total $\mathrm{H}_{2}$ evolution reached $33 \mathrm{mmol}$. Without the deposition of Pt NPs, Ti-MOF-NH 2 showed a much lower activity than Pt/Ti-MOF-NH . These results therefore suggested the presence of the Pt NPs led to an increase in the efficiency of the charge separation process, which played an important role in enhancing the efficiency of the $\mathrm{H}_{2}$ production reaction.

In 2013, Wu's group [64] reported the preparation of a novel Pd@UiO-66( $\left.\mathrm{NH}_{2}\right)$ nanocomposite using a facile one-pot hydrothermal approach. The results of this study showed that the textural properties of UiO-66( $\left.\mathrm{NH}_{2}\right)$ were strongly affected by the Pd modification process, which lead to significant improvements in the photocatalytic activity. The resulting Pd@UiO-66 $\left(\mathrm{NH}_{2}\right)$ exhibited excellent reusability properties and higher visible-light photocatalytic activity towards the reduction of $\mathrm{Cr}(\mathrm{VI})$ compared with UiO-66( $\left.\mathrm{NH}_{2}\right)$. These improvements in the properties of the catalyst were attributed to the high dispersion of Pd NPs and their close contact within the matrix, which led to enhanced light harvesting and the efficient separation of the photogenerated electron-hole pairs. Most notably, Pd@UiO-66( $\left.\mathrm{NH}_{2}\right)$ could be used for the simultaneous photocatalytic degradation of organic pollutants, such as MO and methylene blue (MB), and the reduction of $\mathrm{Cr}(\mathrm{VI})$ with even greater activity in the binary system. The simultaneous activity of this system could be attributed to the synergetic effects of the photocatalytic oxidation and reduction pathways, which would consume the photogenerated holes and electrons, respectively (Fig. 12). This work was the first reported example of the use of a MOF-based material as a dual functional photocatalyst for the simultaneous removal of different categories of pollutant.

Several methods have been developed to anchor metal NPs onto the surfaces of MOFs, including chemical vapor deposition [95], liquid/incipient-wetness impregnation [96], solid grinding [97] and microwave irradiation [98]. Although these methods have their own advantages, there are still several inherent limitations. The synthetic strategies described above also suffer from a number of drawbacks, including their requirements for complicated multi-step synthesis; the use of organic stabilizers
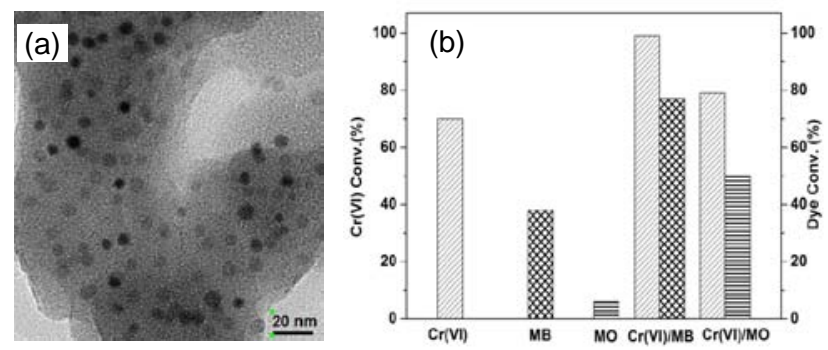

Fig. 12. (a) TEM image for Pd@UiO-66(NH2). (b) Simultaneous photocatalytic reduction of $\mathrm{Cr}(\mathrm{VI})$ and degradation of dyes (10 ppm) on Pd@UiO-66 $\left(\mathrm{NH}_{2}\right)$ under visible-light irradiation. Reproduced with permission from Ref. [64]. Copyright 2013, RSC.

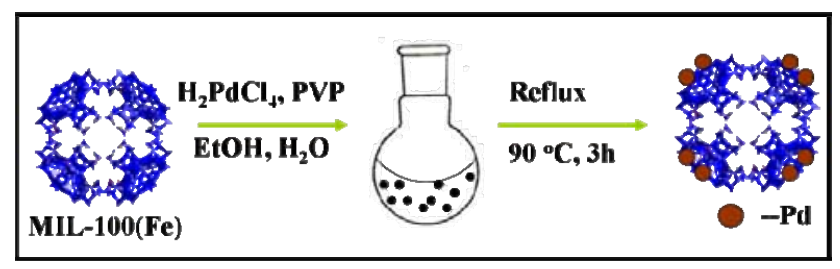

Fig. 13. Overall flowchart for the fabrication of Pd@MIL-100(Fe) using an alcohol reduction approach. Reproduced with permission from Ref. [65]. Copyright 2015, Elsevier.

to control the morphological and size distribution characteristics of the products; and the using strong reducing agent such as $\mathrm{NaBH}_{4}$.To solve these problems, $\mathrm{Wu}$ and co-workers [65] developed a facile alcohol reduction approach for immobilizing highly dispersed Pd NPs on MIL-100(Fe) (Fig. 13). In a typical experiment, MIL-100(Fe), $\mathrm{H}_{2} \mathrm{PdCl}_{4}$ solution, PVP, ethanol and $\mathrm{H}_{2} \mathrm{O}$ were added to a round bottom flask, and the resulting suspension was heated at $90{ }^{\circ} \mathrm{C}$ with stirring for $3 \mathrm{~h}$. This process afforded Pd@MIL-100(Fe) as a brown powder, which was washed with ethanol and dried under a steady stream of $\mathrm{N}_{2}$.TEM images showed that the integrity of the MIL-100(Fe) structure remained unchanged following this process. The tiny Pd NPs resulting from this process had particle sizes in the range of 6-10 $\mathrm{nm}$ and were homogeneously dispersed over the MIL-100(Fe) (Fig. 14). The resulting nanocomposite Pd@MIL-100(Fe) exhibited high photoactivity towards the degradation of three typical pharmaceutical and personal care products (PPCPs), including theophylline, ibuprofen and bisphenol A, under visible-light irradiation $(\lambda \geq 420 \mathrm{~nm})$. Notably, this result was better than that of the blank-MIL-100(Fe). This work was the first reported example of the use of MOF-based photocatalysts for the removal of aqueous PPCPs.

In a separate study, Wu et al. [66] reported the fabrication of
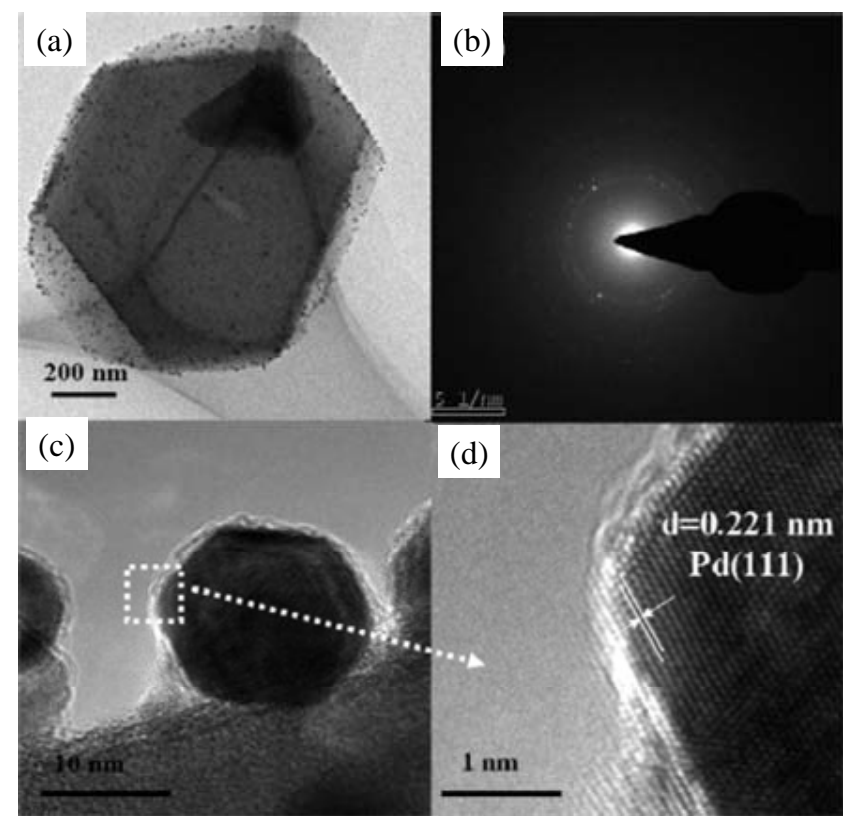

Fig. 14. TEM image (a), SAED pattern (b) and HRTEM images (c and d) of Pd@MIL-100(Fe). Reproduced with permission from Ref. [65]. Copyright 2015, Elsevier. 
metal@MIL-100(Fe) (metal = Au, Pd, and Pt) nanocomposites via the anchoring of noble metal NPs onto the surface of MIL-100(Fe) through a facile photodeposition method. Notably, this method did not require the addition of reducing agents or organic ligands as stabilizers. The irradiation of a dispersion of MIL-100(Fe) in absolute ethanol with visible light $(\lambda \geq 420 \mathrm{~nm})$ led to the formation of photogenerated holes, which were scavenged by ethanol while the photogenerated electrons were trapped by metal ions. The resulting M@MIL-100(Fe) (M = Au, $\mathrm{Pd}$, and $\mathrm{Pt}$ ) nanocomposites showed enhanced photoactivities towards the photocatalytic degradation of MO and the reduction of $\mathrm{Cr}(\mathrm{VI})$ under visible-light irradiation compared with blank-MIL-100(Fe). The enhanced activity of this material could be attributed to the formation of a Schottky barrier following the addition of the different noble metals to MIL-100(Fe). In this case, the photoelectrons would be readily transferred from MIL-100(Fe) to the $\mathrm{Au}$, Pd or Pt NPs, which would lead to a significant improvement in the separation and lifetime of the photogenerated carriers, and ultimately improve of photocatalytic activity of MIL-100(Fe).

More recently, Wu's group [67] reported a facile, new $\mathrm{Ti}^{3+}$-assisted synthetic method for the direct growth of noble metal NPs (Au, Pd, Pt) on MIL-125(Ti). According to this method, their radiation of a dispersion of MIL-125(Ti) in methanol led to the formation of $\mathrm{Ti}^{3+}$ ions on the surface of MIL-125(Ti). These $\mathrm{Ti}^{3+}$ ions exhibited strong reducing power, which allow them to react directly with the oxidative noble-metal salts in the absence of an additional reducing agent (Fig. 15). Moreover, the reduction position of this material could be controlled based on the periodic arrangement of titanium-oxygen nodes within the MOF, leading to a homogeneous distribution of noble metal NPs in the absence of a stabilizing agent. The in-situ reduction of noble metal precursors by photoinduced $\mathrm{Ti}^{3+}$ would also lead to the formation of strong interactions between the noble metals and the titanium-oxygen clusters, which would have a beneficial effect on the transfer of photogenerated charge carriers and therefore enhance the photocatalytic activity of the sample. The photocatalytic selective oxidation of benzyl alcohol to benzaldehyde and the degradation of RhB over M/MIL-125(Ti) (M = Au, Pd, Pt) have been studied in detail. The M/MIL-125(Ti) composites exhibited enhanced photoactivity compared with blank MIL-125(Ti). To highlight the benefits of this method for the synthesis of metal NP/MOFs and further explore the potential photocatalytic applications of

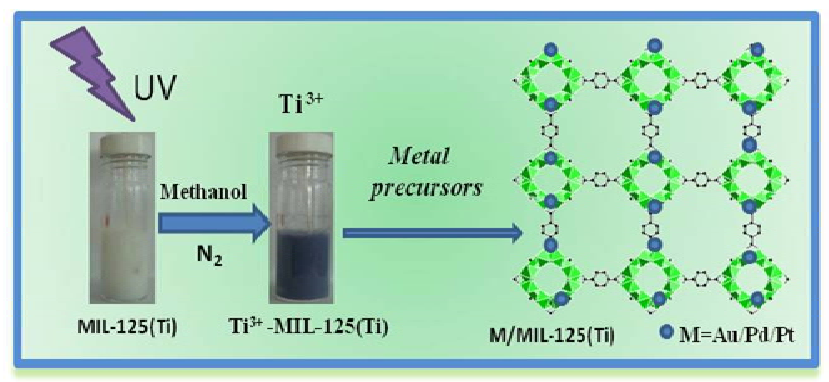

Fig. 15. Schematic presentation for the synthesis of M/MIL-125(Ti) (M $=\mathrm{Au}, \mathrm{Pd}, \mathrm{Pt}$ ) composites. Reproduced with permission from Ref. [67]. Copyright 2015, ACS.
Pt/MIL-125(Ti), the authors also investigated the production of $\mathrm{H}_{2}$ from an aqueous solution containing triethanolamine as a sacrificial agent. The results showed that the Pt/MIL-125(Ti) material prepared using this $\mathrm{Ti}^{3+}$-assisted method exhibited superior activity compared with a sample prepared via a direct photodeposition method. Significantly, the strategy reported in this study is a general technique that could be extended to the decoration of MIL-125(Ti) with other metals, such as $\mathrm{Ag}$ and $\mathrm{Ni}$, or other MOFs containing metals with variable valence states.

\subsubsection{MOFs decorated with carbon materials}

The integration of carbon materials with MOFs is another important approach for the development of novel photocatalysts, with graphene oxide (GO) and reduced graphene oxide (RGO) representing ideal candidates. As photosensitizers, GO and RGO can be used to extend the photoresponse regions of MOFs from the ultraviolet to the visible light region. Furthermore, the high conductivity of these materials can facilitate the rapid transport of photogenerated electrons and prevent their recombination with photogenerated holes. Lastly, the large surface areas and excellent absorption capacities of GO and RGO make them ideal carriers for the preparation of composite materials [99-104].

Luo and co-workers [68] reported their work towards the synthesis of MIL-88 (Fe) with GO via a rapid single step method. Briefly, a mixture of $\mathrm{Fe}\left(\mathrm{NO}_{3}\right)_{3} \cdot 9 \mathrm{H}_{2} \mathrm{O}$ and $\mathrm{H}_{2} \mathrm{BDC}$ was dispersed in DMF by sonication for 120 min. GO powder was then dispersed in the same suspension with vigorous stirring. After that, the mixture was heated at $85^{\circ} \mathrm{C}$ in an oil bath under shaking. After cooling to room temperature, the reaction mixture was filtered and washed thoroughly with ethanol and deionized water before being dried. The resulting MIL-88(Fe)@G0 composites exhibited rapid $\mathrm{MB}$ and $\mathrm{RhB}$ degradation performances with the almost complete degradation of these substrates within 20 and $30 \mathrm{~min}$, respectively. These catalytic activities were much higher than those of pure MIL-88(Fe) (50 min for $\mathrm{MB}$ and $60 \mathrm{~min}$ for $\mathrm{RhB}$ ) and GO (40 min for MB and $\mathrm{RhB})$.

The utilization of the surface charges of MOFs and GO for the fabrication of reduced graphene oxide-MOF (RGO-MOFs) nanocomposites was recently reported by $\mathrm{Wu}$ and co-workers [69]. In this particular study, the authors developed a simple and flexible electrostatic self-assembly strategy for the fabrication of GO-MOF nanocomposites. According to this strategy, the introduction of $\mathrm{NH}_{2}$-functional groups into UiO-66 led to the formation of positive charges, which were subjected to a further assembly process with the oppositely charged GO particles. A subsequent hydrothermal reduction process gave a series of novel RGO-UiO-66( $\left.\mathrm{NH}_{2}\right)$ materials. TEM images showed that the integrity of the $\mathrm{UiO}-66\left(\mathrm{NH}_{2}\right)$ structure remained unchanged following the introduction of RGO. Notably, some of the UiO-66 $\left(\mathrm{NH}_{2}\right)$ NPs appeared to be "wrapped-up" by the RGO and showed strong interfacial contacts (Fig. 16), which suggested that this simple electrostatic self-assembly strategy could be used to form strong interfacial contacts between two separate ingredients. These interactions not only led to a significant increase in the visible-light absorption properties of 


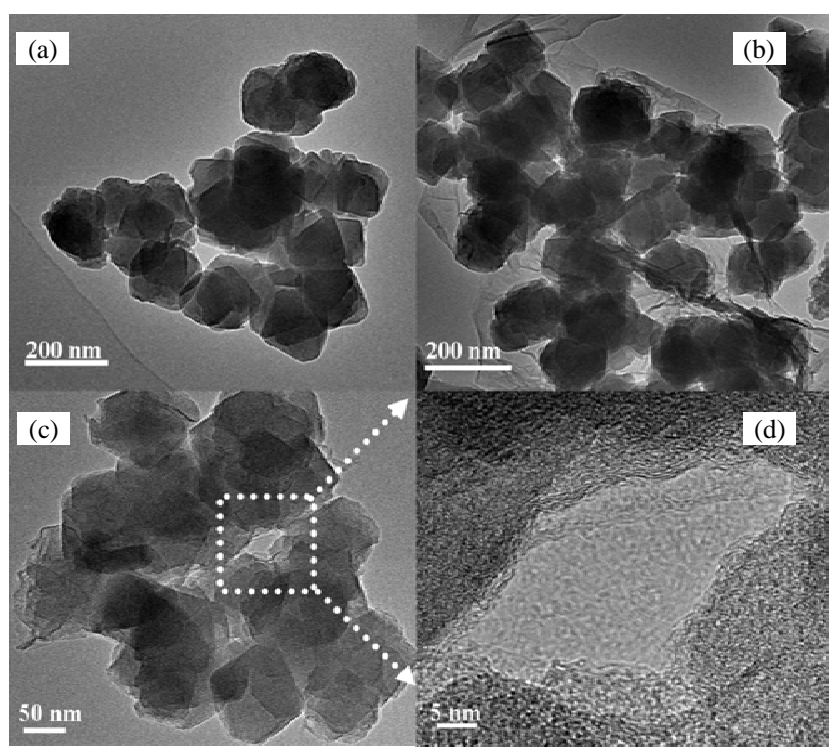

Fig. 16. TEM images for UiO-66 $\left(\mathrm{NH}_{2}\right)$ (a) and RGO-UiO-66 $\left(\mathrm{NH}_{2}\right)$ (b and c). HRTEM image of RGO-UiO-66(NH2) (d). Reproduced with permission from Ref. [69]. Copyright 2014, RSC.

these materials but also led to greater efficiency in the separation of the photogenerated electron-hole pairs. Consequently, the resulting RGO-UiO-66 $\left(\mathrm{NH}_{2}\right)$ exhibited significantly improved photocatalytic activity towards the reduction of aqueous $\mathrm{Cr}(\mathrm{VI})$ to $\mathrm{Cr}(\mathrm{III})$ under visible-light illumination compared with pristine UiO-66 $\left(\mathrm{NH}_{2}\right)$. This work was the first reported example of the fabrication of GO-MOFs using an electrostatic self-assembly strategy and their subsequent application to photocatalysis. Moreover, the authors believed that the present self-assembly approach could be extended to the preparation of other MOF-based hybrids.

Continuing with this line of enquiry, $\mathrm{Wu}$ and co-workers [70] conducted additional research into the nature of the interfacial contacts between the MOFs and RGO, with particular emphasis on the relationship between the contracts and the photocatalytic activity. MIL-53(Fe) was selected as a model system for this study because of its high stability, adjustability and photo responsiveness [105]. RGO-MIL-53(Fe) (denoted as M53-RG0) was fabricated via an efficient electrostatic self-assembly method to improve the interfacial contact between RGO and the MIL-53(Fe). To develop a better understanding of the advantages of the electrostatic self-assembly approach for improving the photoactivity of M53-RGO nanocomposites, the authors selected the photocatalytic reduction of $\mathrm{Cr}(\mathrm{VI})$ as a model reaction. After $80 \mathrm{~min}$ of visible-light illumination $(\lambda \geq 420 \mathrm{~nm})$, the reduction ratio of $\operatorname{Cr}(\mathrm{VI})$ rapidly increased to $100 \%$, which was much higher than the ratio achieved over D-M53-RGO (direct synthesis of MIL-53(Fe)-reduced graphene oxide nanocomposites via a one-pot solvothermal approach). Combined photoelectrochemical analyses suggested that the introduction of RGO led to a reduction in the recombination of photogenerated electron-hole pairs. Furthermore, the formation of effective interfacial contacts between the MIL-53(Fe) and RGO surfaces accelerated the transfer of photogenerated electrons, leading to the observed increase in the photocatalytic activity of M53-RG0 toward the target reactions.

\subsection{Coupling MOFs with semiconductors}

All though MOFs are intrinsically photoactive, there is still considerable scope for improving their activities. The coupling of two semiconductors with matched band gaps has been proven to be a feasible approach for reducing the recombination probability of photogenerated electrons and holes, and this approach has been widely investigated extensively as a strategy for improving the photocatalytic activity of semiconductor photocatalysts [106-109]. This strategy could also be applied to MOFs. Moreover, several recent publications have highlighted the superior properties of MOFs coupled with semiconductors. The key advantages of these systems can be highlighted as follows: (1) the use of MOFs as a matrix allows for some control over the size of the semiconductor particles; (2) the high specific surface areas of MOFs can be used to create more catalytic sites and form better contacts between the reactants and the active sites; and (3) the porous nature of the host MOFs can also provide extra pathways for the migration of photoinduced electrons and therefore facilitate the effective separation of the charge carriers $[110,111]$. As a result, fabricating semiconductor@MOF heterostructures can not only retain and enhance the functionalities of the MOFs and semiconductor, but can also generate new functionalities as a consequence of their synergistic effects.

In 2013, Wu and co-workers [71] reported for the first time the development of a facile room-temperature photodeposition technique for the direct photodeposition of $\mathrm{CdS}$ onto UiO-66 $\left(\mathrm{NH}_{2}\right)$ using the electrons produced by UiO-66 $\left(\mathrm{NH}_{2}\right)$ under visible-light illumination.The properties of the rod-like $\mathrm{CdS}$ generated in this way could be tuned based on the irradiation time and optical band gap of the CdS- $\mathrm{NH}_{2}-\mathrm{UiO}-66$ nanocomposites. The photocatalytic performances of the resulting CdS-UiO-66 $\left(\mathrm{NH}_{2}\right)$ nanocomposites were evaluated towards the selective oxidation of various alcohol substrates using molecular oxygen as a benign oxidant. The results demonstrated that the CdS-UiO-66 $\left(\mathrm{NH}_{2}\right)$ nanocomposites were stable and capable of acting as promising visible-light-driven photocatalysts for the selective oxidation of alcohols to the corresponding aldehydes under mild conditions (Table 2). The alcohol conversion levels over CdS-UiO-66 $\left(\mathrm{NH}_{2}\right)$ were also higher than those achieved over UiO-66( $\left.\mathrm{NH}_{2}\right)$, CdS and CdS-UiO-66( $\left.\mathrm{NH}_{2}\right)$, which were prepared by simply mixing the appropriate amounts of CdS and UiO-66 $\left(\mathrm{NH}_{2}\right)$ under identical reaction conditions. The high photocatalytic activity of CdS-UiO-66( $\left.\mathrm{NH}_{2}\right)$ could be attributed to the combined interaction and effective transportation of the photogenerated electron-hole pairs, as well as a faster interfacial charge-transfer rate. Thus, this work not only provided a mild and simple method for using MOFs as supports, but also provided a platform for coupling charge-carrier transporting systems to narrow band gap metal sulfides to give novel composite systems. Inspired by this work, Wu's group subsequently fabricated two highly efficient visible light-driven-photocatalysts for the evolution of hydrogen using 
Table 2

Results for the photocatalytic aerobic oxidation of various alcohols over CdS-UiO-66( $\left.\mathrm{NH}_{2}\right)$.

\begin{tabular}{|c|c|c|c|c|}
\hline Entry & Substrate & Product & $\begin{array}{c}\text { Conversion } \\
(\%)\end{array}$ & $\begin{array}{c}\text { Selectivity } \\
(\%)\end{array}$ \\
\hline 1 & $\mathrm{H}_{2} \mathrm{OH}$ & & 30.12 & $>99$ \\
\hline 2 & $\mathrm{CH}_{2}$ & & 32.17 & 98 \\
\hline 3 & $\mathrm{CH}_{2}$ & & 63.20 & 95 \\
\hline 4 & $\mathrm{CH}_{2} \mathrm{C}$ & & 32.25 & 95 \\
\hline 5 & $\mathrm{CH}_{2}$ & & 21.50 & $>99$ \\
\hline 6 & $\mathrm{CH}_{2} \mathrm{O}$ & & 23.18 & $>99$ \\
\hline
\end{tabular}

UiO-66 and CdS, as well as a two-dimensional material as a co-catalyst. In 2014, Wu's group reported the design and preparation of the ternary composite UiO-66/CdS/RGO and its subsequent application to the photocatalytic production of $\mathrm{H}_{2}$ [112]. The photocatalytic hydrogen evolution rate of UiO-66/CdS/RGO was 13.8 times greater than that of pure commercial CdS. Moreover, UiO-66/CdS/RGO showed several advantages over the reference composite photocatalyst P25/CdS/1\%RGO. In 2015, Wu's group fabricated $\mathrm{MoS}_{2} / \mathrm{UiO}-66 / \mathrm{CdS}$ as a novel photocatalyst [110]. This composite functioned as a high-performance photocatalyst for the evolution of $\mathrm{H}_{2}$ under visible-light irradiation, even in the absence of a noble-metal co-catalyst, because of the synergetic catalytic effects of UiO-66, $\mathrm{MoS}_{2}$ and $\mathrm{CdS}$. The $\mathrm{H}_{2}$ production rate over $\mathrm{MoS}_{2} / \mathrm{UiO}-66 / \mathrm{CdS}$ was almost 60 times higher than the rate recorded over pure $\mathrm{CdS}$ and also exceeded that of $\mathrm{Pt} / \mathrm{UiO}-66 / \mathrm{CdS}$ under the same reaction conditions. More importantly, $\mathrm{MoS}_{2} / \mathrm{UiO}-66 / \mathrm{CdS}$ displayed much higher photostability than CdS.

In terms of the practical application of any catalyst, the recover and recyclability represent important characteristics. The development of photocatalysts that can be readily separated from a reaction mixture and reused in a subsequent run is therefore highly desired. Jiang et al. [72] described the development of $\mathrm{Fe}_{3} \mathrm{O}_{4} @ \mathrm{MIL}-100(\mathrm{Fe})$ core-shell microspheres as a novel type of magnetic recyclable photocatalyst, which was fabricated in a controllable manner using a versatile layer-by-layer strategy (Fig. 17). SEM images showed that the blank $\mathrm{Fe}_{3} \mathrm{O}_{4}$ particles and $\mathrm{Fe}_{3} \mathrm{O}_{4} @ \mathrm{MIL}-100(\mathrm{Fe})$ microspheres were both spherical in shape. Furthermore, TEM investigations revealed that the $\mathrm{Fe}_{3} \mathrm{O}_{4} @ \mathrm{MIL}-100(\mathrm{Fe})$ microspheres formed in this way were composed of an $\mathrm{Fe}_{3} \mathrm{O}_{4}$ core and a MOF shell, which was consistent with the formation of a core-shell structure. The photocatalytic activity of the $\mathrm{Fe}_{3} \mathrm{O}_{4} @ M I L-100(\mathrm{Fe})$ core-shell microspheres was evaluated towards the decolorization of an aqueous solution of MB under UV-vis light and visi-
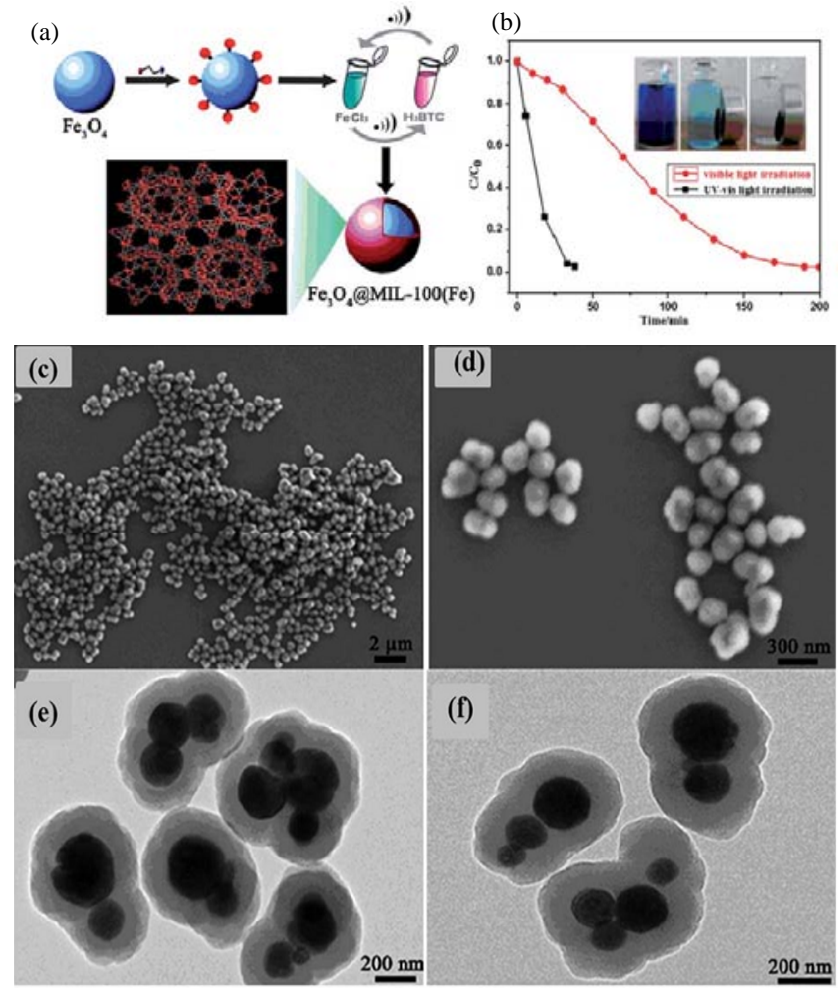

(f)

Fig. 17. Illustration of the synthesis of the $\mathrm{Fe}_{3} \mathrm{O}_{4} @ \mathrm{MIL}-100(\mathrm{Fe})$ core-shell microspheres (a) and their application as a magnetically-separable photocatalyst for the degradation of MB under UV-vis and visible light (b); SEM and TEM images of the $\mathrm{Fe}_{3} \mathrm{O}_{4} @ M I L-100(\mathrm{Fe})$ core-shell microspheres (c-f). Reproduced with permission from Ref. [72]. Copyright 2013, RSC.

ble-light irradiation. The results demonstrated that $\mathrm{Fe}_{3} \mathrm{O}_{4} @ \mathrm{MIL}-100(\mathrm{Fe})$ was an efficient platform for the photodegradation of MB. It was also found that $\mathrm{Fe}_{3} \mathrm{O}_{4} @ M I L-100(\mathrm{Fe})$ showed higher activity than $\mathrm{Fe}_{3} \mathrm{O}_{4}$ under the same conditions. Notably, although the $\mathrm{Fe}_{3} \mathrm{O}_{4} @ \mathrm{MIL}-100(\mathrm{Fe})$ composite did not show any obvious improvement in activity compared with MIL-100(Fe), it could be readily separated from the reaction by the application of a magnetic field. This result therefore suggested that this core-shell microsphere system could be used as a convenient and highly recyclable photocatalyst in numerous practical applications. Moreover, $\mathrm{Fe}_{3} \mathrm{O}_{4} @ \mathrm{MIL}-100(\mathrm{Fe})$ showed comparable and, in some cases, better photocatalytic activity towards the degradation of MB compared with several existing photocatalysts, such as $\mathrm{TiO}_{2}$ and $\mathrm{C}_{3} \mathrm{~N}_{4}$ under similar reaction condition. Taken together, these results implied that this magnetic core-shell photocatalyst could be used as a green and inexpensive catalyst in large scale applications for the photocatalytic degradation of dyes.

The major challenge currently preventing MOF composites from achieving their full potential is the development of simple and efficient assembly techniques. Ye and co-workers [75] recently reported a facile method for the synthesis of a UiO-66/carbon nitride nanosheet (UiO-66/CNNS) hybrid structure by the electrostatic self-assembly of negatively charged CNNS with positively charged UiO-66. The activities of the samples were evaluated towards the photocatalytic reduc- 
tion of $\mathrm{CO}_{2}$ under mild reaction conditions using TEOA as an electron donor. As shown in Fig. 18(a), the highest photocatalytic CO evolution rate was attained over the UiO-66/CNNS composite. Following $6 \mathrm{~h}$ of visible-light illumination, the $\mathrm{CO}$ yield was $59.4 \mu \mathrm{mol} \mathrm{g}_{\mathrm{CN}^{-1}}$, which was over three times greater than the yield recorded over CNNS $\left(17.1 \mu \mathrm{mol} \mathrm{gCN}^{-1}\right)$. Moreover, these results showed that the UiO-66/CNNS composite photocatalyst exhibited reproducible photocatalytic activity for all three cycles (Fig. 18(b)). The authors also demonstrated that the electrons from the photoexcited CNNS could transfer to UiO-66, which would substantially suppress electron-hole pair recombination in the carbon nitride nanosheet, as well as supplying long-lived electrons for the reduction of the $\mathrm{CO}_{2}$ molecules adsorbed in UiO-66. As a result, the Ui0-66/carbon nitride nanosheet heterogeneous photocatalyst exhibited a much higher photoactivity for the conversion of $\mathrm{CO}_{2}$ than that of bare carbon nitride nanosheets.

Compared with $\mathrm{Zr}$, Ti and Fe-based MOFs, there have been very few reports pertaining to the use of MIL-101(Cr) in photocatalysis. The lack of reports in this case has been attributed to the large band gap energy and facile recombination of the photogenerated electrons $\left(\mathrm{e}^{-}\right)$and holes $\left(\mathrm{h}^{+}\right)$, which strongly inhibit the photocatalytic efficiency of MIL-101(Cr). Wei and co-workers [73] recently reported the combination of MIL-101(Cr) with $\mathrm{BiVO}_{4}$ to give a composite material via a coordination reaction-induced self-assembly process. The resulting semiconductor-MOF nanocomposite was evaluated for the degradation of RhB using visible-light irradiation and showed higher photocatalytic activity than its individual components or physical mixtures of these materials. Photoluminescence emission spectroscopy revealed that the introduction of $\mathrm{BiVO}_{4}$ minimized the recombination of photogenerated electron-hole pairs. $\mathrm{BiVO}_{4}$ and the $\mathrm{BiVO}_{4} / \mathrm{MIL}-101(\mathrm{Cr})$ nanocomposite were also explored for the degradation of colorless benzoic acid under visible-light irradiation. As expected, the $\mathrm{Bi}$ $\mathrm{VO}_{4} / \mathrm{MIL}-101(\mathrm{Cr})$ composite exhibited higher photocatalytic activity. In an effort to discover more efficient visible-light responsive photocatalysts, Wang and co-workers [74] recently integrated $\mathrm{Ag} / \mathrm{AgCl}$ with $\mathrm{ZIF}-8$ to develop an efficient photocatalyst for the degradation of RhB. ZIF-8 was chosen as the support material in this case because of its large specific surface area, reversible guest trapping and excellent thermal and (a)

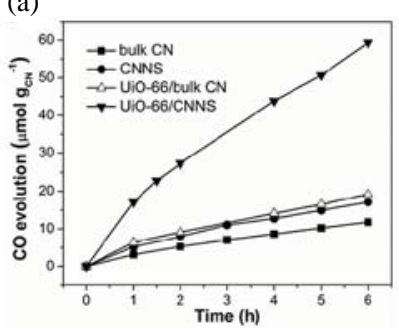

(b)

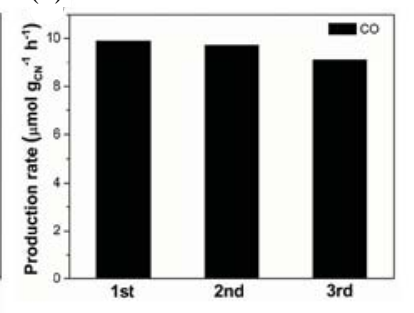

Fig. 18. (a) Time courses for the evolution of CO over bulk CN, CNNS, UiO-66/bulk CN and UiO-66/CNNS photocatalysts. (b) Production yields of CO over UiO-66/CNNS to measure the reproducibility through cycling tests. The carbon nitride content was $10 \mathrm{wt} \%$ for the hybrid structures. Reproduced with permission from Ref. [75]. Copyright 2015 Wiley. chemical stability properties. These results therefore demonstrated that the Ag/AgCl@ZIF-8 photocatalysts exhibited high levels of activity and durability towards the decomposition of RhB under visible-light irradiation and sunlight (Fig. 19(a)). Moreover, as shown in Fig. 19(b), the Ag/AgCl@ZIF-8 hybrid materials showed noticeable and stable photocurrents under visible-light irradiation, which indicated that the electrons and holes from these hybrid materials had low recombination rates. More significantly, this work was the first reported example of the integration of a plasmonic photocatalyst with MOFs.

Several other semiconductor-MOF composites have also been developed, including Co-ZIF-9/CdS [113], HKUST-1/TiO and $\mathrm{ZIF}-8 / \mathrm{Zn}_{2} \mathrm{GeO}_{4}$, which have been proven to be beneficial for photocatalytic reactions [114,115]. Taken together, these studies have provided a solid platform for the development of MOF-based superconductor systems for heterogeneous photocatalysis and allowed for the facile and effective conversion of solar energy.
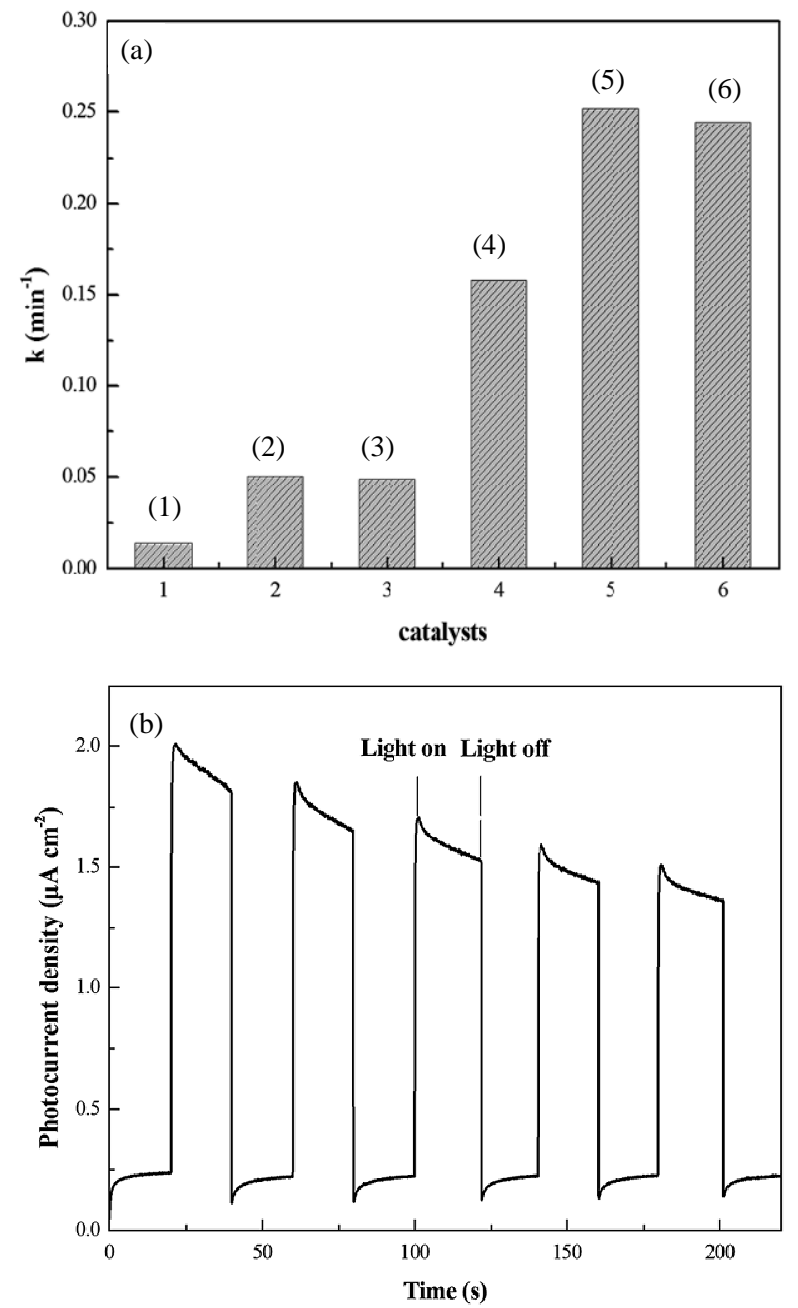

Fig. 19. (a) Degradation rate constant of $\mathrm{RhB}$ for a variety of different samples. (1) P25; (2) Ag/AgCl; (3) Pure ZIF-8; (4) $20 \mathrm{wt} \%$ Ag/AgCl@ZIF-8; (5) 35 wt\% $\quad$ Ag/AgCl@ZIF-8 (6) $50 \quad$ wt $\%$ Ag/AgCl@ZIF-8. (b) Photoelectric conversion performance of $35 \mathrm{wt} \%$ $\mathrm{Ag} / \mathrm{AgCl} @ Z \mathrm{ZIF}-8$ in 0.1 mol/L $\mathrm{Na}_{2} \mathrm{SO}_{4}$ aqueous solution under $300 \mathrm{~W} \mathrm{Xe}$ lamp irradiation. Reproduced with permission from Ref. [74]. Copyright 2014, RSC. 


\section{Conclusions and prospective}

It is envisaged that solar energy conversion technologies based on photocatalysts will play an important role in solving environmental pollution and energy shortage problems. MOFs possess a broad range of unique characteristics, and have consequently emerged as novel materials with significant potential for photocatalysis. MOF-based heterogeneous photocatalysts have recently been investigated extensively in terms of their application to dye degradation, water-splitting, $\mathrm{CO}_{2}$ photoreduction and organic photosynthesis processes. These applications were mainly derived from the consideration of MOFs as semiconductors. In general, the efficiency of a photocatalyst is greatly affected by its optical absorption and charge separation efficiency properties, as well as the number of catalytic sites. This review has provided a brief summary of recent developments involving the use of MOFs as photocatalysts, with particular emphasis on several key strategies (i.e., ligand functionalization, photosensitization of MOFs, co-catalyst engineering, and coupling MOFs with semiconductors), which have been developed to achieve high efficiency MOF-based photocatalysts. Although several impressive results have been achieved in MOF-based photocatalysis, research towards MOF-mediated photocatalysis still remains in its infancy, and significant improvements are still required to make these systems fully competitive. Although a large number of MOFs has been synthesized, most of the activity reported in the field to date has been focused on their application to gas adsorption. Furthermore, only a small number of MOFs have been applied to the field of photocatalysis. There are, therefore, still numerous opportunities for the development of novel MOF-based photocatalytic materials, such as MOFs containing redox active metals and/or functional organic linkers. From a catalytic perspective, the development of reaction-stable MOFs is highly desired. MOFs constructed from carboxylate ligands and $\mathrm{Zn}^{2+}, \mathrm{Cd}^{2+}$ or $\mathrm{Co}^{2+}$ cations as SBUs generally suffer from poor chemical stability and are not always suitable for photocatalysis. The poor stability of these systems has been attributed to their ions showing higher affinities for water molecules than the carboxylate ligands, making the corresponding frameworks unstable to water. The poor stability of these MOFs has greatly limited their application in liquid-phase photocatalytic process such as hydrogen production from water splitting. However, the use of hard metal ions (high valance metals) such as $\mathrm{Cr}^{3+}, \mathrm{Fe}^{3+}, \mathrm{Al}^{3+}$, $\mathrm{Ti}^{4+}, \mathrm{V}^{4+}$ and $\mathrm{Zr}^{4+}$, with hard bases containing donor atoms ( $\mathrm{O}$ or N) tends to afford MOFs with satisfactory thermal, chemical and water stability properties. In most cases, the structural integrity of the MOFs remained intact during the initial modification and subsequent photocatalytic reaction processes. Although numerous studies have been reported pertaining to the reusability of MOF-based photocatalysts, only a few have focused on providing a comparison of the turnover number and turnover frequency characteristics of these catalysts versus other photocatalysts. Photocatalyst deactivation can be evaluated by textural and spectroscopic techniques. Furthermore, the leaching of metallic or organic components from MOFs into the reaction medium during a reaction is undesirable and can be confirmed by the chemical analysis of the reaction filtrate or other research tools.

Most of the MOF-based photocatalysts reported in the literature are typically used for the oxidative degradation of dyes and there is therefore an urgent need to expand the scope of these systems top other unexplored areas of research. Furthermore, the photocatalytic activities of most of the MOFs reported to date remain unsatisfactory, and there is too strong a reliance on the inclusion of sacrificial agents such as TEOA for photocatalytic $\mathrm{H}_{2}$ generation and $\mathrm{CO}_{2}$ reduction reaction. This reliance on additives is not green or economical and represents a significant limitation to the practical application of these systems. Finally, given that the chemical and electronic properties of MOF-based materials differ considerably from those of classical semiconductors, the traditional photocatalytic mechanism has not been matched by exponential increases in publications regarding these novel photocatalysts. The reaction mechanisms of MOF-based photocatalysts therefore need to be investigated in greater detail. Although many challenges still exist in this area, the rapid development of MOF composites in recent years bodes well for a bright future for these new functional materials. With sustained research efforts towards this exciting field, it is envisaged that these materials will soon achieve their potential as photocatalysis.

\section{References}

[1] Fujishima A, Honda K. Nature, 1972, 238: 37

[2] Liang S J, Wen L R, Lin S, Bi J H, Feng P Y, Fu X Z, Wu L. Angew Chem Int Ed, 2014, 53: 2951

[3] Fox M A, Dulay M T. Chem Rev, 1993, 93: 341

[4] Liu Y C, Xing M Y, Zhang J L. Chin J Catal (刘允昌, 刑明阳, 张金龙. 催化学报), 2014, 35: 1511

[5] Kudo A, Miseki Y. Chem Soc Rev, 2009, 38: 253

[6] Wang M Y, Ioccozia J, Sun L, Lin J C, Lin Z Q. Energy Environ Sci, 2014, 7: 2182

[7] Liu G, Yang H G, Pan J, Yang Y Q, Lu G Q, Cheng H M. Chem Rev, 2014, 114: 9559

[8] Yu J G, Yu X X. Environ Sci Technol, 2008, 42: 4902

[9] Zeng H B, Cai W P, Liu P S, Xu X X, Zhou H J, Klingshirn C, Kalt H. ACS Nano, 2008, 2: 1661

[10] Hou J G, Wang Z, Kan W B, Jiao S Q, Zhu H M, Kumar R V. J Mater Chem, 2012, 22: 7291

[11] Wu W M, Liu G D, Xie Q H, Liang S J, Zheng H R, Yuan R, Su W Y, Wu L. Green Chem, 2012, 14: 1705

[12] Xiang Q J, Cheng B, Yu J G. Appl Catal B, 2013, 138-139: 299

[13] Xu L, Xia J X, Wang K, Wang L G, Li H M, Xu H, Huang L Y, He M Q, Dalton Trans, 2013, 42: 6468

[14] Li Q, Guo B, Yu J G, Ran J R, Zhang B H, Yan H J, Gong J R. J Am Chem Soc, 2011, 133: 10878

[15] Hernandez-Alonso M D, Fresno F, Suarez S, Coronado J M. Energy Environ Sci, 2009, 2: 1231

[16] Nasalevich M A, Becker R, Ramos-Fernandez E V, Castellanos S, Veber S L, Fedin M V, Kapteijn F, Reek J N H, van der Vlugt J I, Gascan J. Energy Environ Sci, 2015, 8: 364

[17] Wu T B, Zhang P, Ma J, Fan H L, Wang W T, Jiang T, Han B X. Chin J Catal (吴天斌, 张鹏, 马珺, 㚞红雷, 王伟涛, 姜涛, 韩布兴. 催化学 报), 2013, 34: 167

[18] Collins D J, Zhou H-C. J Mater Chem, 2007, 17: 3154

[19] Liu J, Strachan D M, Thallapally P K. Chem Commun, 2014, 50: 466 


\section{Graphical Abstract}

Chin. J. Catal., 2015, 36: 2071-2088 doi: 10.1016/S1872-2067(15)60984-6

\section{Strategies for engineering metal-organic frameworks as efficient photocatalysts}

Lijuan Shen, Ruowen Liang, Ling $\mathrm{Wu}^{*}$

Fuzhou University; Fujian Institute of Research on the Structure of Matter, Chinese Academy of Sciences

This review provides a detailed summary of the material properties affecting the photocatalytic activities of MOFs, as well as current strategies for enhancing their photoactivities, including ligand functionalization, photosensitization and co-catalysts engineering.

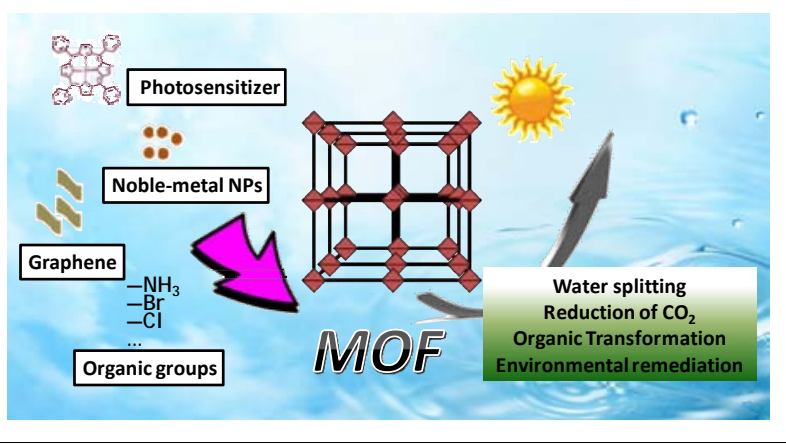

[20] Tanh Jeazet H B, Staudt C, Janiak C. Dalton Trans, 2012, 41: 14003

[21] Guo Z Y, Xu H, Su S Q Cai J F, Dang S, Xiang S C, Qian G D, Zhang H J, O'Keeffe M, Chen B L. Chem Commun, 2011, 47: 5551

[22] Chen B L, Wang L B, Xiao Y Q, Fronczek F R, Xue M, Cui Y J, Qian G D. Angew Chem Int Ed, 2009, 48: 500

[23] Lee J, Farha O K, Roberts J, Scheidt K A, Nguyen S T, Hupp J T. Chem Soc Rev, 2009, 38: 1450

[24] Wu C-D, Lin W. Angew Chem Int Ed, 2007, 46: 1075

[25] Llabrés i Xamena F X, Casanova O, Galiasso Tailleur R, Garcia H, Corma A. J Catal, 2008, 255: 220

[26] Corma A, García H, Llabrés i Xamena F X. Chem Rev, 2010, 110: 4606

[27] Choi J R, Tachikawa T, Fujitsuka M, Majima T. Langmuir, 2010, 26 : 10437

[28] Horiuchi Y, Toyao T, Takeuchi M, Matsuoka M, Anpo M. Phys Chem Chem Phys, 2013, 15: 13243

[29] Wang S B, Yao W S, Lin J L, Ding Z X, Wang X C. Angew Chem Int Ed 2014, 53: 1034

[30] Li S, Huo F. Nanoscale, 2015, 7: 7482

[31] Johnson J A, Luo J, Zhang X, Chen Y-S, Morton M D, Echeverría E, Torres F E, Zhang J. ACS Catal, 2015: 5283

[32] Alvaro M, Carbonell E, Ferrer B, Llabrés i Xamena F X, Garcia H. Chem Eur J, 2007, 13: 5106

[33] Jiang D M, Mallat T, Krumeich F, Baiker A.J Catal, 2008, 257: 390

[34] Hasegawa S, Horike S, Matsuda R, Furukawa S, Mochizuki K, Kinoshita Y, Kitagawa S. J Am Chem Soc, 2007, 129: 2607

[35] Kovtunov K V, Zhivonitko V V, Corma A, Koptyug I V. J Phys Chem Lett, 2010, 1: 1705

[36] Wang J L, Wang C, Lin W B. ACS Catal, 2012, 2: 2630

[37] Zhang T, Lin W B. Chem Soc Rev, 2014, 43: 5982

[38] Wang C C, Li J R, Lv X L, Zhang Y Q, Guo G. Energy Environ Sci, 2014, 7: 2831

[39] Wang S B, Wang X C. Small, 2015, 11: 3097

[40] Wang C C, Zhang Y Q Li J, Wang P.J Mol Struct, 2015, 1083: 127

[41] Fuentes-Cabrera M, Nicholson D M, Sumpter B G, Widom M. J Chem Phys, 2005, 123: 124713

[42] Bordiga S, Lamberti C, Ricchiardi G, Regli L, Bonino F, Damin A, Lillerud K P, Bjorgen M, Zecchina A. Chem Commun, 2004: 2300

[43] Tachikawa T, Choi J R, Fujitsuka M, Majima T. J Phys Chem C, 2008, 112: 14090

[44] Du J J, Yuan Y P, Sun J X, Peng F M, Jiang X, Qiu L G, Xie A J, Shen Y H, Zhu J F. J Hazard Mater, 2011, 190: 945

[45] Wu P Y, He C, Wang J, Peng X J, Li X Z, An Y L, Duan C Y.J Am Chem Soc, 2012, 134: 14991
[46] Pu S, Xu L, Sun L, Du H B. Inorg Chem Commun, 2015, 52: 50

[47] Mohaghegh N, Tasviri M, Rahimi E, Gholami M R. Appl Surf Sci, 2015, 351: 216

[48] Wang H, Yuan X Z, Wu Y, Zeng G M, Chen X H, Leng L J, Li H. Appl Catal B, 2015, 174-175: 445

[49] Wang H, Yuan X Z, Wu Y, Zeng G M, Chen X H, Leng L J, Wu Z B, Jiang L B, Li H.J Hazard Mater, 2015, 286: 187

[50] Zhou J J, Wang R, Liu X L, Peng F M, Li C H, Teng F, Yuan Y P. Appl Surf Sci, 2015, 346: 278

[51] Zhang S Q, Li L N, Zhao S G, Sun Z H, Hong M C, Luo J H. J Mater Chem A, 2015, 3: 15764

[52] Yang J H, Wang D G, Han H X, Li C. Acc Chem Res, 2013, 46: 1900

[53] Fu Y H, Sun D R, Chen Y J, Huang R K, Ding Z X, Fu X Z, Li Z H. Angew Chem Int Ed, 2012, 51: 3364

[54] Shen L J, Liang S J, Wu W M, Liang R W, Wu L. Dalton Trans, 2013, 42: 13649

[55] Shen L J, Liang R W, Luo M B, Jing F F, Wu L. Phys Chem Chem Phys, 2015, 17: 117

[56] Zhou T H, Du Y H, Borgna A, Hong J D, Wang Y, Han J Y, Zhang W, Xu R. Energy Environ Sci, 2013, 6: 3229

[57] Toyao T, Saito M, Dohshi S, Mochizuki K, Iwata M, Higashimura H, Horiuchi Y, Matsuoka M. Chem Commun, 2014, 50: 6779

[58] Nasalevich M A, Goesten M G, Savenije T J, Kapteijn F, Gascon J. Chem Commun, 2013, 49: 10575

[59] He J, Wang J Q Chen Y J, Zhang J P, Duan D L, Wang Y, Yan Z Y. Chem Commun, 2014, 50: 7063

[60] Yang H, He X-W, Wang F, Kang Y, Zhang J. J Mater Chem, 2012, 22: 21849

[61] Wen M C, Kuwahara Y, Mori K, Zhang D Q, Li H X, Yamashita H. J Mater Chem A, 2015, 3: 14134

[62] Sun D R, Liu W J, Qiu M, Zhang Y F, Li Z H. Chem Commun, 2015, 51: 2056

[63] Horiuchi Y, Toyao T, Saito M, Mochizuki K, Iwata M, Higashimura H, Anpo M, Matsuoka M. J Phys Chem C, 2012, 116: 20848

[64] Shen L J, Wu W M, Liang R, Lin R, Wu L. Nanoscale, 2013, 5: 9374

[65] Liang R W, Luo S G, Jing F F, Shen L J, Qin N, Wu L. Appl Catal B, 2015, 176-177: 240

[66] Liang R W, Jing F F, Shen L J, Qin N, Wu L. Nano Res, 2015, 8: 3237

[67] Shen L J, Luo M B, Huang L J, Feng P Y, Wu L. Inorg Chem, 2015, 54 : 1191

[68] Wu Y, Luo Hanjin, Wang H. RSC Adv, 2014, 4: 40435

[69] Shen L J, Huang L J, Liang S J, Liang R W, Qin N, Wu L. RSC $A d v$, 2014, 4: 2546

[70] Liang R W, Shen L J, Jing F F, Qin N, Wu L. ACS Appl Mater 
Interfaces, 2015, 7: 9507

[71] Shen L J, Liang, S J, Wu W M, Liang R W, Wu L. J Mater Chem A, 2013, 1: 11473

[72] Zhang C F, Qiu L G, Ke F, Zhu Y J, Yuan Y P, Xu G S, Jiang X. J Mater Chem A, 2013, 1: 14329

[73] Xu Y L, Lv M M, Yang H B, Chen Q, Liu X T, Wei F Y. RSC Adv, 2015, 5: 43473

[74] Gao S J, Liu W H, Shang N Z, Feng C, Wu Q H, Wang Z, Wang C. RSC $A d v, 2014,4: 61736$

[75] Shi L, Wang T, Zhang H B, Chang K, Ye J H. Adv Funct Mater, 2015, 25: 5260

[76] Nasalevich M A, van der Veen M, Kapteijn F, Gascon J. CrystEngComm, 2014, 16: 4919

[77] Dan-Hardi M, Serre C, Frot T, Rozes L, Maurin G, Sanchez C, Férey G. J Am Chem Soc, 2009, 131: 10857

[78] Hendon C H, Tiana D, Fontecave M, Sanchez C, D’arras L, Sassoye C, Rozes L, Mellot-Draznieks C, Walsh A. J Am Chem Soc, 2013, 135: 10942

[79] Cavka J H, Jakobsen S, Olsbye U, Guillou N, Lamberti C, Bordiga S, Lillerud K P. J Am Chem Soc, 2008, 130: 13850

[80] Fateeva A, Chater P A, Ireland C P, Tahir A A, Khimyak Y Z, Wiper P V, Darwent J R, Rosseinsky M J. Angew Chem Int Ed, 2012, 51: 7440

[81] Tran P D, Wong L H, Barber J, Loo J S C. Energy Environ Sci, 2012, 5: 5902

[82] Vinodgopal K, Wynkoop D E, Kamat P V. Environ Sci Technol, 1996, 30: 1660

[83] Takanabe K, Kamata K, Wang X C, Antonietti M, Kubota J, Domen K. Phys Chem Chem Phys, 2010, 12: 13020

[84] Taira S, Miki T, Yanagi H. Appl Surf Sci, 1999, 143: 23

[85] Yuan Y P, Yin L S, Cao S W, Xu G S, Li C H, Xue C. Appl Catal B, 2015, 168-169: 572

[86] Ni Y H, Zhu Y, Ma X. Dalton Trans, 2011, 40: 3689

[87] Liu S, Guo E Y, Yin L M.J Mater Chem, 2012, 22: 5031

[88] Xiong Z, Wang H B, Xu N Y, Li H L, Fang B Z, Zhao Y C, Zhang J Y, Zheng C G. Int J Hydrogen Energ, 2015, 40: 10049

[89] Zhu Q L, Xu Q. Chem Soc Rev, 2014, 43: 5468

[90] Toyao T, Saito M, Horiuchi Y, Mochizuki K, Iwata M, Higashimura H, Matsuoka M. Catal Sci Technol, 2013, 3: 2092

[91] Zhou W, Li T, Wang J Q, Qu Y, Pan K, Xie Y, Tian G H, Wang L, Ren Z Y, Jiang B J, Fu H G. Nano Res, 2014, 7: 731

[92] Bouhadoun S, Guillard C, Dapozze F, Singh S, Amans D, Bouclé J, Herlin-Boime N. Appl Catal B, 2015, 174-175: 367
[93] Chen J J, Wang W K, Li W W, Pei D N, Yu H Q. ACS Appl Mater Interfaces, 2015, 7:12671

[94] Nguyen N T, Altomare M, Yoo J E, Schmuki P. Adv Mater, 2015, 27: 3208

[95] Hermes S, Schröter M-K, Schmid R, Khodeir L, Muhler M, Tissler A, Fischer R W, Fischer R A. Angew Chem Int Ed, 2005, 44: 6237

[96] Gu X J, Lu Z H, Jiang H L, Akita T, Xu Q. J Am Chem Soc, 2011, 133: 11822

[97] Ishida T, Nagaoka M, Akita T, Haruta M. Chem Eur J, 2008, 14: 8456

[98] El-Shall M S, Abdelsayed V, Khder A E R S, Hassan H M A, El-Kaderi H M, Reich T E. J Mater Chem, 2009, 19: 7625

[99] Yang M Q, Zhang N, Pagliaro M, Xu Y J. Chem Soc Rev, 2014, 43: 8240

[100] An X Q,Yu J C. RSC Adv, 2011, 1: 1426

[101] Yang M Q, Xu Y J.J Phys Chem C, 2013, 117: 21724

[102] Yang M Q, Zhang N, Xu Y J. ACS Appl Mater Interfaces, 2013, 5: 1156

[103] Zhang J, Yu J, Jaroniec M, Gong J R. Nano Lett, 2012, 12: 4584

[104] Han C, Chen Z, Zhang N, Colmenares J C, Xu Y-J. Adv Funct Mater, 2015, 25: 221

[105] Liang R W, Jing F F, Shen L J, Qin N, Wu L. J Hazard Mater, 2015, 287: 364

[106] Zhang X, Zhang N, Xu Y J, Tang Z-R. New J Chem, 2015, 39: 6756

[107] Zhang J Y, Wang Y H, Jin J, Zhang J, Lin Z, Huang F, Yu J G. ACS Appl Mater Interfaces, 2013, 5: 10317

[108] Wang X F, Li S F, Ma Y Q Yu H G, Yu J G. J Phys Chem C, 2011, 115 : 14648

[109] Chen X F, Zhang J, Huo Y N, Li H X. Chin J Catal (陈小芳, 张佳, 霍 宇凝, 李和兴. 催化学报), 2013, 34: 949

[110] Shen L, Luo M, Liu Y, Liang R, Jing F, Wu L. Appl Catal B, 2015, 166-167: 445

[111] Peng R, Wu C M, Baltrusaitis J, Dimitrijevic N M, Rajh T, Koodali R T. Chem Commun, 2013, 49: 3221

[112] Lin R, Shen L J, Ren Z Y, Wu W M, Tan Y X, Fu H R, Zhang J, Wu L. Chem Commun, 2014, 50: 8533

[113] Wang S B, Wang X C. Appl Catal B, 2015, 162: 494

[114] Li R, Hu J H, Deng M S, Wang H L, Wang X J, Hu Y L, Jiang H L, Jiang J, Zhang Q, Xie Y, Xiong Y J. Adv Mater, 2014, 26: 4783

[115] Liu Q, Low Z X, Li L X, Razmjou A, Wang K, Yao J F, Wang H T. J Mater Chem A, 2013, 1: 11563

\title{
MOFs光催化材料的设计和调控
}

\author{
沈丽娟, ${ }^{\mathrm{a}, \mathrm{c}}$, 梁若雯 ${ }^{\mathrm{a}}$, 吴 棱a, , * \\ a福州大学能源与环境光催化国家重点实验室, 福建福州350002 \\ $\mathrm{b}$ 中国科学院福建物质结构研究所结构化学国家重点实验室, 福建福州 350002 \\ c福州大学化肥催化剂国家工程研究中心, 福建福州350002
}

摘要: 环境污染和能源短缺是制约当今社会发展的重大问题. 光催化技术可直接利用太阳能驱动一系列重要的化学反应, 具有能 耗低、反应条件温和、无二次污染等优点, 是解决这一问题的有效途径. 实现这个过程的关键在于寻找设计高效的光催化剂. 目前, 光催化材料主要由无机半导体组成, 其结构的改造和修饰难度很大, 难以根据实际需要来控制其大小、形状以及物理化学特性. 而 有机化合物具有优良的分子剪裁与修饰的功能, 但它们却在坚固性与稳定性等方面具有明显的缺点. 因此如果能发展既具有无机 化合物的稳定性又具有有机化合物的可剪裁与修饰性的新型光催化材料,无疑将促进光催化的发展和应用.

金属-有机骨架材料(Metal-Organic Frameworks, MOFs)正是这样一类结合了无机物的稳定性和有机物的可修饰性的杂化材 料. MOFs 是一类以金属阳离子为节点、有机配体为连接体的多孔配位聚合物的总称. 这类材料不仅拥有超高的比表面积、丰富的 拓扑结构,而且其结构兼具可剪裁性、可设计性、易调变等特点,在气体吸附储存、分离、传感等领域都有广泛的应用. 在催化领 
域MOFs也显示出巨大的应用前景: (1)比表面积大, 有利于对反应底物的吸附, 促进催化反应的进行; (2)组成多样, 结构具可剪裁 性、可设计性、易调变等特点,通过对其金属单元或者配体进行改变修饰,可以实现对MOFs结构和性能的调变; (3)MOFs中金属氧单元之间由有机配体隔开,相当于分立的半导体量子点, 在反应中不易发生团聚. 并且各个分立的金属-氧单元之间可能存在协 同效应,有利于保持催化剂的稳定性和产生高的催化活性. 因此, MOFs材料是一类非常有潜力的异相催化剂. 光催化是一类典型 的多相催化技术, 与传统半导体光催化材料相比, MOFs由于具有可在分子水平进行灵活调控的优点, 在光催化领域的应用更有优 势. 此外, MOFs结构上的确定性为研究催化剂的界面电荷迁移和光催化机理提供了便利条件, 通过对其构-效关系的研究和光催 化反应机理的探索反过来有助于我们从微观尺度上进一步认识光催化的本质.

MOFs 材料在光催化领域已经有了初步的研究. 越来越多的MOFs材料被成功应用于光催化降解染料、选择性转化有机物、光 解水制氢和 $\mathrm{CO}_{2}$ 还原等反应. 典型的有MOF-5、UiO-66和MIL-125系列等. 近年来, 已有少量的文献综述了MOFs 这类材料在光催化 领域的研究. 这些文献主要围绕MOFs在光催化过程中所起到的作用, 比如作为催化剂、助催化剂或载体来展开; 或者是从MOFs 的光催化应用领域, 比如污染物降解、产氢、二氧化碳还原、有机物转化来分类展开. 本文围绕如何设计合成高效的MOFs光催 化剂, 综述了近年来国内外关于提高MOFs的光催化性能而开展的相关研究工作, 包括理论研究MOFs的能级结构及化学性质、在 MOFs配体上修饰官能团调变其能带结构、染料或者金属化合物光敏化MOFs提高其光吸收性能、负载金属/碳材料及半导体复合 提高光生载流子的分离效率等. 最后, 本文对MOFs光催化剂的未来发展趋势进行了展望, 强调开发新型的MOFs光催化剂, 并加 强对MOFs光催化机制的研究, 有助于指导现有MOFs催化剂的改良和设计新型光催化剂.

关键词: 金属-有机骨架材料; 光催化; 配体; 功能化; 光敏化; 助催化剂; 复合材料

收稿日期: 2015-08-29. 接受日期: 2015-09-24. 出版日期: 2015-12-20.

*通讯联系人. 电话: (0591)83779105; 传真: (0591)83779105; 电子信箱: wuling@fzu.edu.cn

基金来源：国家自然科学基金(21273036, 21177024); 国家重点基础研究发展计划(973计划)资助项目(2014CB239303).

本文的英文电子版由Elsevier出版社在ScienceDirect上出版(http://www.sciencedirect.com/science/journal/18722067). 